Universidad de Lima

Escuela de Posgrado

Maestría en Tributación y Política Fiscal

\title{
PRINCIPALES CONTROVERSIAS DEL RÉGIMEN TRIBUTARIO DEL IMPUESTO A LA RENTA APLICABLE A LAS ENTIDADES SIN FINES DE LUCRO
}

Trabajo de investigación para optar el Grado Académico de Maestro en Tributación y Política Fiscal

\section{Daniel Job Delgado Pérez}

Código 20152598

\author{
Asesores \\ Silvia León \\ Ronald Vargas
}

Lima - Perú

Mayo 2019 


\section{PRINCIPALES CONTROVERSIAS DEL RÉGIMEN TRIBUTARIO DEL IMPUESTO A LA RENTA APLICABLE A LAS ENTIDADES SIN FINES DE LUCRO}




\section{TABLA DE CONTENIDO}

\section{INTRODUCCIÓN}

1

\section{CAPÍTULO I: MARCO GENERAL DE LAS ENTIDADES SIN}

FINES DE LUCRO EN EL PERÚ ................................................4

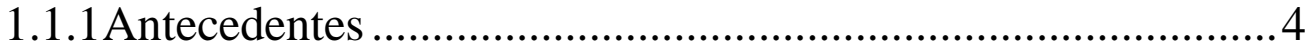

1.1.1Entidades lucrativas y entidades no lucrativas ........................5

1.2.1Estamentos establecidos en la Constitución respecto a las

Entidades Sin Fines de Lucro..........................................................

1.2.2Disposiciones establecidas en el Código Civil peruano ..........9

1.2.3Conceptos esenciales aplicables a las entidades no lucrativas 10

\section{CAPÍTULO II: RÉGIMEN TRIBUTARIO APLICABLE A LAS ENTIDADES SIN FINES DE LUCRO EN EL IMPUESTO A LA

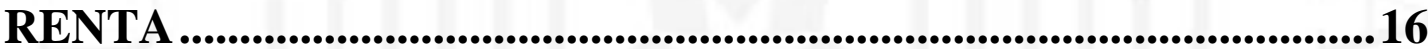

2.1 La hipótesis de incidencia del Impuesto a la Renta en las entidades no lucrativas 16

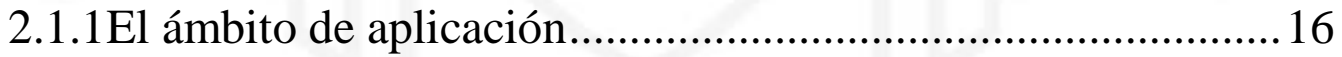

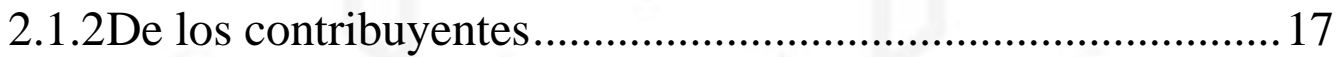

2.2 De los sujetos e ingresos inafectos ........................................... 17

2.3 La exoneración de las entidades sin fines de lucro.................... 19

2.3.1 Normas establecidas en la Ley del Impuesto a la Renta..........19

2.3.2Consideraciones establecidas en el Reglamento de la Ley del

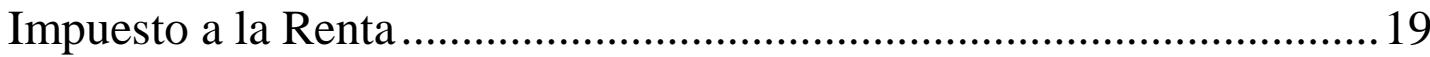

2.4 Requisitos sustanciales para gozar de la exoneración ...............20

2.4.1 Los fines sujetos a la exoneración ............................................20

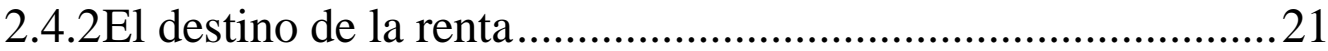

2.4.3La no disposición directa ni indirecta de las rentas .................22 
2.4.4La contemplación del destino del patrimonio en caso de disolución

\section{CAPÍTULO III: CONTROVERSIAS EN MATERIA DEL} TRATAMIENTO DEL IMPUESTO A LA RENTA DE LAS ENTIDADES SIN FINES DE LUCRO

3.1 Controversia respecto al instrumento de constitución: Fines o actividades empresariales que realizan las Entidades Sin Fines de Lucro 24

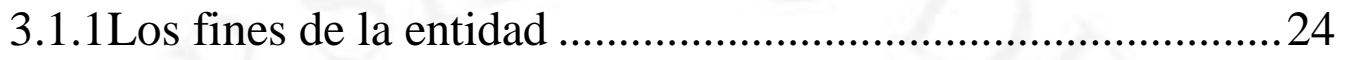

3.1.2 La permisividad de las actividades comerciales .....................26

3.2 Controversia respecto al concepto del destino de las rentas.....30

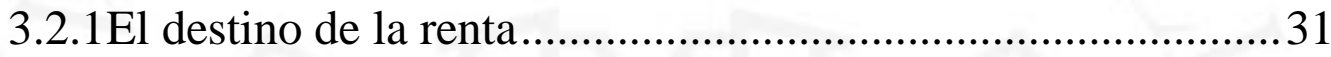

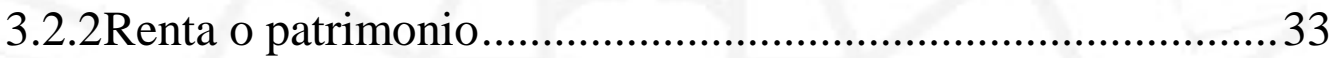

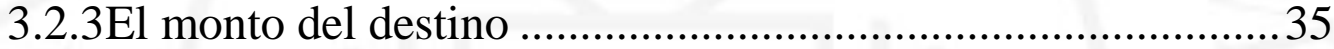

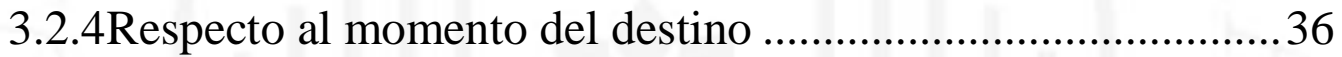

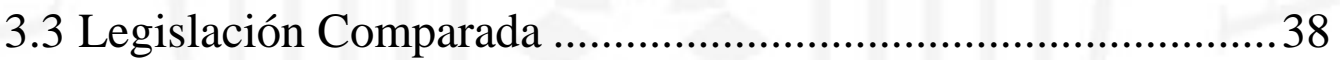

3.3.1 Tratamiento fiscal español de las entidades no lucrativas .......38

3.3.2Tratamiento fiscal mexicano de las entidades no lucrativas...46

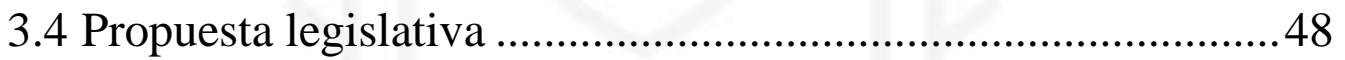

3.4.1 Modificación de la Ley del Impuesto a la Renta ......................48

3.4.2Inclusión en el Reglamento del Impuesto a la Renta...............52

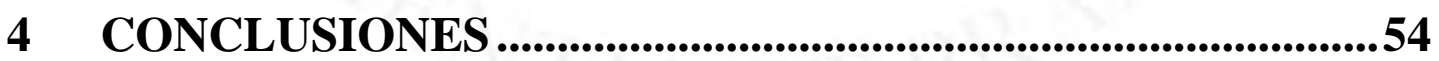

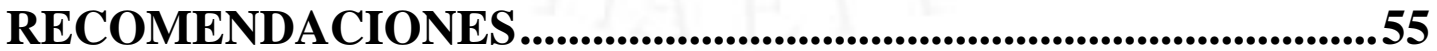




\section{ÍNDICE DE TABLA}

Tabla 3.1 Ingreso Anual recaudados. Tributos Internos por actividad económica y tributo 


\section{INTRODUCCIÓN}

Las entidades sin fines de lucro siempre han estado presentes en nuestra sociedad; por esta razón, el Estado ha incentivado y establecido una legislación que esté acorde a las operaciones de estas. Ya en la Constitución Política del Perú de 1979 se había establecido el derecho de las personas a asociarse y crear fundaciones y, con el mismo propósito, la Constitución Política de 1993 incorporó una condición adicional en el actuar de estas entidades: Que tengan un comportamiento no lucrativo. Este aspecto es desarrollado con mayor amplitud en el Código Civil peruano de 1984, en el que se deja establecido el carácter no lucrativo de dichas entidades.

Por su parte, de acuerdo a las legislaciones del impuesto a la renta del Perú, desde la Ley No 5574 Contribución sobre la Renta, promulgada en 1927, hasta el actual TUO de la Ley del Impuesto a la Renta aprobado por el Decreto Supremo No 179-2004-EF, el Estado peruano, de acuerdo a su política fiscal, viene otorgando el beneficio de la exoneración del impuesto a las renta a las rentas de las entidades no lucrativas, por los menos por dos principales razones: Un primer grupo de estas entidades ejerce una función de colaboradores estratégicos del Estado, pues sus actividades cumplen la finalidad de satisfacer las necesidades sociales de terceros. Un segundo grupo es aquél cuyas entidades buscan resolver las propias necesidades de sus miembros. En ambos casos, estas entidades bajo ninguna forma persiguen fines lucrativos.

Las entidades no lucrativas, en sus inicios, se constituyeron con fines estrictamente benéficos o de apoyo social y, por lo general, sus ingresos provenían de donaciones o ayudas humanitarias; por lo cual, su desarrollo estaba ausente de actividades empresariales, limitándose solo a actividades íntimamente vinculadas a sus fines sociales. Sin embargo, gracias a factores como el crecimiento económico del país, estas han dado lugar al desarrollo de diversas actividades comerciales o empresariales que guardan mucha distancia de los fines primigenios establecidos en su constitución. Hoy, muchas entidades no lucrativas han dado un giro radical respecto a sus operaciones, pasando de ser entidades sostenidas por la recepción de donaciones o aporte de sus asociados a instituciones financieramente auto-sostenibles con significativos volúmenes de operaciones empresariales cada vez más complejas. 
Este nuevo escenario, que se viene manifestando en las entidades no lucrativas, hace reflexionar sobre la permisividad, establecida en la legislación peruana para desarrollar actividades empresariales y si en realidad se justifican los objetivos por los que el Estado otorgó el beneficio de la exoneración del impuesto a la renta. En este trabajo de investigación verificamos que las actividades comerciales permitidas por la Ley del Impuesto a la Renta y avaladas por el Tribunal Fiscal, en sí no presentan inconsistencias tributarias ni tampoco, conceptualmente, deberían generar un problema económico para la caja fiscal, debido a que tanto las rentas provenientes de las actividades empresariales como las no empresariales, según nuestra legislación, deben de ser destinadas al fin de las entidades no lucrativas. Sin embargo, el problema se patentiza cuando llega el momento en que las entidades no lucrativas deben cumplir el requisito de "destinar las rentas a sus fines" establecido en el inciso b) del artículo $19^{\circ}$ de la Ley del Impuesto a la Renta.

La ex jefa de la SUNAT, Tania Quispe, comentó en el año 2014 que "hay más de 50 mil asociaciones sin fines de lucro en la mira de la SUNAT” (Gestión, 2014, pág. 18), esto debido a que en los últimos años muchas entidades vienen operando como no lucrativas, pero que en el fondo son empresas, en razón de los mecanismos que elaboran para retirar el dinero antes de determinar la utilidad de la entidad no lucrativa. Entre ellas se encuentran las universidades, las Organizaciones No Gubernamentales (ONGs), los colegios profesionales, las instituciones deportivas, entre otras. La modalidad consiste en que estas entidades, aprovechando la flexibilidad de la ley respecto al desarrollo de actividades comerciales, vienen destinando fondos de la entidad a dichas actividades, aduciendo que dichas entregas son inversiones y, en esencia, no calzan con el concepto de destino de la renta; esto, por lo tanto, no estaría expresamente prohibido en la ley.

En este escenario, muchas entidades no lucrativas vienen derivando fondos a las actividades empresariales, fondos que se quedan por largos años en manos de gestores empresariales, en muchos casos sin retorno de la inversión, pero que, finalmente, termina beneficiando a las actividades empresariales que, en el fondo, el Estado no hubiera deseado favorecer.

Por las razones expuestas, este trabajo de investigación aborda la controversia que existe entre el requisito del "destino de la renta a los fines específicos" establecidos en el inciso b) del artículo $19^{\circ}$ de la Ley del Impuesto a la Renta y su aplicación al momento de determinar si, efectivamente, la renta se ha destinado al fin de acuerdo a las 
perspectivas del Estado al momento de establecer la exoneración. Este trabajo de investigación, analiza si la legislación o jurisprudencia vigente puede vislumbrar una definición que sea suficiente para determinar si la renta ha sido destinada al fin social o si es necesario incluir una nueva definición o parámetros más precisos en la Ley del Impuesto a la Renta.

Para lograr lo expresado, en el Capítulo I se desarrolla el marco conceptual de las entidades sin fines de lucro según lo establecido en el ordenamiento jurídico peruano. En el Capítulo II se describe la normativa de las entidades sin fines de lucro establecidas en la Ley del Impuesto a la Renta y se analizan los cuatro requisitos establecidos para el goce de la exoneración, enfocándose en el requisito denominado destino de la renta a los fines específicos en el país. En el Capítulo III se describe la controversia del requisito denominado destino de la renta establecido en la ley, evaluando si la legislación actual del Impuesto a la Renta o la jurisprudencia permiten determinar el cumplimiento del referido requisito a fin de obtener la exoneración del impuesto, o si es necesario elaborar una propuesta legislativa para resolver la controversia. 


\section{CAPÍTULO I: MARCO GENERAL DE LAS ENTIDADES SIN FINES DE LUCRO EN EL PERÚ}

\subsection{El desarrollo de las Entidades Sin Fines de Lucro en el Perú}

\subsubsection{Antecedentes}

\section{- Los inicios de las Entidades Sin Fines de Lucro en el Perú}

En el Perú, las entidades sin fines de lucro, respecto a la obtención de sus rentas, en un primer momento han actuado, por lo menos, de dos formas: Un grupo de entidades, como las ONG, se constituyeron con fines netamente benéficos de ayuda humanitaria a favor de terceras personas, normalmente de extrema pobreza, damnificados por los desastres naturales, entre otros; debido a dicha naturaleza, su única fuente de financiamiento o renta era la proveniente de donaciones. Un segundo grupo, por ejemplo, los colegios profesionales, se han venido formalizando con el objetivo de atender a un fin social en común, por lo que su fuente de financiamiento o renta provenían netamente de los aportes de sus miembros asociados. Desde sus inicios, estos grupos de entidades no lucrativas solo estaban enfocadas en el cumplimiento de sus fines, sin desarrollar actividades empresariales ajenas a sus fines y es, en este contexto, en el que se establecieron las normas relacionadas con las entidades no lucrativas en el país.

Un segundo momento se produjo al finalizar los años 90, cuando las principales instituciones internacionales de desarrollo como la Organización Mundial de las Naciones Unidas (ONU), la Agencia Internacional para el Desarrollo (USAID), el Banco Mundial (BM), la Organización Económica de Cooperación y Desarrollo (OECD), entre otras instituciones internacionales, declararon que el Perú está fuera de la relación de los denominados países de extrema pobreza, pues se nota un paulatino, pero notorio crecimiento económico del país. Esa circunstancia da lugar a un doble impacto: El primero tiene efecto directo en las ONG, pues la reducción de las ayudas humanitarias y de beneficencia dejan sin recursos a estas organizaciones, quienes rápidamente dan paso a la auto-sostenibilidad, orientando sus recursos al desarrollo de programas de autogeneración de fondos. El segundo impacto es el incremento de entidades no lucrativas con diversos fines sociales, desarrollando actividades cada vez más lejanas de sus propios fines, con el ánimo de recaudar más fondos para su entidad. 


\section{- La era de los programas de auto-sostenibilidad}

Con el crecimiento económico, un grupo de entidades no lucrativas, como las ONGs, empezó a trabajar con programas de auto-generación de recursos, siendo uno de los más importantes los de financiamiento de dinero para proyectos de pequeña inversión, entre los que destacan los Bancos Comunales, Mujer Emprendedora, Programas Agrícolas, Jóvenes Emprendedores, Fomento a las PYMES, etc., todos estos con la misma dinámica de préstamos de dinero y retorno del capital más los intereses. En este actuar, uno de los programas que acrecentó el número de prestamistas y multiplicó sus utilidades fue el de los Bancos Comunales quienes, en sus inicios, estaban conformados por pequeños grupos de mujeres; en la actualidad lo conforman miles de participantes, convirtiendo a las entidades no lucrativas en posición económica similar a una institución financiera con dimensiones capaces de competir con instituciones del mercado financiero.

En paralelo, las demás asociaciones civiles como los colegios, universidades, gremios, colegios profesionales, instituciones deportivas, etc., por la permisividad de la legislación tributaria, vienen incursionando en cuanta actividad empresarial se les presenten para generar ingresos, obteniendo considerables utilidades, muchas veces superiores a las rentas provenientes de los fines.

\subsubsection{Entidades lucrativas y entidades no lucrativas}

\section{- Las empresas}

El Diccionario de la Real Academia Española (2018) define a la empresa como "unidad de organización dedicada a actividades industriales, mercantiles o prestación de servicios con fines lucrativos".

Socías y Herranz (2013) manifiestan:

Entidades lucrativas. Son aquellas que se constituyen con la intención de obtener un beneficio económico y persiguen el interés particular de sus socios. Son las de denominadas empresas. Por ejemplo, las empresas individuales, societarias mercantiles, sociedades estatales (el estado es propietario mayoritario). (p. 23)

Una característica a resaltar de las empresas es que todas tienen como objetivo el lucro. Las empresas, a través de los aportes de sus socios o accionistas, invierten recursos 
financieros con la finalidad de obtener ganancias de tales inversiones, las cuales se ven materializadas con la obtención de utilidades. Sin embargo, lo que realmente califica como lucro es el acto de disposición de las utilidades de la entidad por parte de sus socios o accionistas, disposición que puede ser efectiva o no, debido a que, si legalmente es factible de disponer de la utilidad, ya ubica a la entidad como una lucrativa.

Las empresas al igual que en las entidades no lucrativas pueden generar utilidades, pero ambas desde su constitución anuncian destinos distintos de sus beneficios. En el caso de las empresas, el destino de las utilidades es la distribución a sus propietarios en calidad de dividendos. Así pues, las empresas desde su constitución, nacen con la finalidad lucrativa, y no pierden tal condición aun cuando no otorguen dividendos e incluso cuando no generen utilidades. A manera de ejemplo, las entidades que deciden constituirse como sociedades anónimas, de acuerdo al artículo $230^{\circ}$ de la Ley $\mathrm{N}^{\circ} 26887$ General de Sociedades, están obligadas al pago de los dividendos a sus accionistas, las cuales se deben de realizar en razón de las utilidades obtenidas en el ejercicio; sin embargo, el hecho de no contar con utilidades y no pagar dividendos no transforma su situación empresarial lucrativa.

En este sentido, una empresa que incluso podría dedicarse a desarrollar fines similares a los de una entidad no lucrativa, por el solo hecho de constituirse como una sociedad mercantil mantendrán siempre su condición de entidad lucrativa.

\section{- Las entidades no lucrativas}

Socías y Herranz (2013) manifiestan: "Entidades no lucrativas. Son aquellas cuya finalidad no es obtener un beneficio económico (aunque pueden tenerlo, pero no repartirlo), sino un beneficio social"' (p. 23).

Arévalo y Hirache (2010) refieren: "De manera preliminar, puede indicarse que entidad sin fines de lucro es la organización cuya finalidad no es la consecución de un beneficio o lucro económico" (p. 10).

En concordancia con la posición de Socías y Herranz, el lucro no se configura con el simple hecho de obtener un beneficio, sino con el acto de disponerlos. Esto quiere decir que las entidades no lucrativas no pierden su condición por el hecho de generar utilidades. 
Las entidades no lucrativas, al igual que las empresas, pueden generar utilidades, pero ambas dan diferentes destinos a estos beneficios. En el caso de entidades no lucrativas, todas sus utilidades son destinadas a sus fines sociales, por lo que los asociados no gozan de dichos beneficios. Así pues, las entidades no lucrativas desde su constitución, nacen con la finalidad no lucrativa, y mantienen su condición aun cuando generen utilidades.

\section{- Principales diferencias}

Arévalo y Hirache (2010) refieren:

De hecho, la gran diferencia entre una entidad sin fines de lucro y una entidad lucrativa no es en estricto la generación del lucro, sino el destino del lucro, esto es, que mientras la entidad no lucrativa se encuentra impedida de distribuir sus beneficios y su patrimonio entre los asociados, las entidades lucrativas se encuentran facultadas a efectuar la distribución de los beneficios económicos obtenidos entre sus socios o trabajadores, según corresponda. (p. 11)

Siguiendo a Arévalo e Hirache, podemos incidir en dos características que se presentan entre una entidad lucrativa y otra no lucrativa:

1) Tanto las entidades lucrativas como las no lucrativas en su accionar pueden generar utilidades.

2) Las entidades lucrativas pueden libremente entregar sus beneficios a sus propietarios, mientras que las no lucrativas están imposibilitadas de hacerlo.

\subsection{Las Entidades Sin Fines de Lucro en el ordenamiento jurídico peruano}

\subsubsection{Estamentos establecidos en la Constitución respecto a las Entidades Sin Fines de Lucro}

La Constitución Política del Perú de 1993 ha establecido estamentos que consagran derechos fundamentales a las personas que deseen asociarse y formalizar instituciones no lucrativas, los cuales a continuación se analizan. 
- El Derecho a la libre asociación y constitución de las entidades no lucrativas de acuerdo al inciso 13$)$ del artículo $2^{\circ}$ de la Constitución Política del Perú (CPP)

La Constitución Política del Perú (1993) ampara el desarrollo de las entidades sin fines de lucro en el Perú, estableciendo como derecho fundamental de la persona: "A asociarse y a constituir fundaciones y diversas formas de organización jurídica sin fines de lucro, sin autorización previa y con arreglo a ley. No pueden ser disueltas por resolución administrativa" (inciso 13, art. 2).

Un primer punto del inciso 13 es que las personas tienen el derecho constitucional de la libre asociación, sin la existencia de previas autorizaciones. Así mismo, queda sin efecto la disolución de las organizaciones sin fines de lucro que provengan de resoluciones administrativas. Con este inciso, la Constitución quiere subrayar el carácter fundamental del derecho citado de que las personas puedan libremente asociarse, organizarse, constituirse y desarrollar operaciones a través de organizaciones no lucrativas.

Un segundo punto del inciso 13 es que la Constitución establece el derecho a la constitución de organizaciones jurídicas de tipo no lucrativo, otorgando viabilidad legal para la formalización, operación y desarrollo de entidades no lucrativas en el Perú. Con este estamento, ninguna norma infraconstitucional, como las leyes, podría restringir el derecho al ejercicio de las entidades no lucrativas.

Un tercer aspecto del inciso 13 es que la Constitución otorga el derecho a constituir organizaciones jurídicas con una condición infranqueable: Que sus fines no persigan el lucro, entendiendo que la restricción prohíbe la distribución de las rentas entre sus asociados o terceros y que, en caso de hacerlo, las entidades perderían su condición de no lucrativas.

- El derecho a la asociación en la vida social de acuerdo al inciso 17) del artículo $2^{\circ}$ de la Constitución Política del Perú (CPP)

La Constitución Política del Perú (1993) ampara el desarrollo de las entidades sin fines de lucro en el Perú, estableciendo como derecho fundamental de la persona: 
A participar, en forma individual o asociada, en la vida política, económica, social y cultural de la Nación. Los ciudadanos tienen, conforme a la ley, los derechos de elección, de remoción o renovación de autoridades, de iniciativa legislativa y de referéndum" (inciso 17, art. 2).

En virtud de este inciso 17, la Constitución otorga a los miembros de las organizaciones, incluidas a las no lucrativas, el derecho a participar activamente en el actuar económico y social, respectivamente. El actuar económico está orientado para las personas que, de manera individual o asociada, desean constituir organizaciones sociales conocidas como no lucrativas cuya finalidad sea atender una necesidad social a través de su organización, usando para ello medios o actividades económicas y sociales, considerando que la utilidad financiera que la organización obtenga sirva para satisfacer un fin social.

\subsubsection{Disposiciones establecidas en el Código Civil peruano}

En el Código Civil peruano de 1984 se describen tres clases de entidades no lucrativas: La asociación, la fundación y el comité. En lo que respecta a este trabajo de investigación se asume lo que este Código ha establecido para las entidades no lucrativas.

\section{- La asociación}

El Código Civil peruano de 1984, define a las asociaciones como: "La asociación es una organización estable de personas naturales o jurídicas, o de ambas, que a través de una actividad en común persigue un fin no lucrativo." (Ministerio de Justicia y Derechos Humanos, 2015, art. 80).

De esta noción, se puede destacar que para el Código Civil las asociaciones se caracterizan por: a) Tener una organización estable, b) contar pluralidad de personas naturales o jurídicas, c) desarrollar una actividad en común, y d) perseguir un fin no lucrativo.

De todas las características enumeradas de la asociación, se advierte que esta organización no es un vehículo para obtener beneficios lucrativos; sin embargo, la caracterización no alcanza a desarrollar una definición singular de lucro, por lo que por medio de esta legislación no se puede definir cuáles son las condiciones para que se 
configure dicho concepto. Asimismo, podemos encontrar que el artículo $82^{\circ}$ establece los contenidos del Estatuto de la asociación y se asevera que los fines deben estar incorporados dentro del corpus de este documento normativo.

El Código Civil peruano, así como para las asociaciones, otorga un similar tratamiento para las fundaciones y los comités, por lo que, evitamos mayor comentario de estas.

\subsubsection{Conceptos esenciales aplicables a las entidades no lucrativas}

En este punto se desarrollan las definiciones más relevantes que son materia de las controversias abordadas en el trabajo de investigación.

\section{- Definición de fines de una asociación no lucrativa}

De acuerdo a la Real Academia (2018) define al fin como: "Objeto o motivo con que se ejecuta algo".

Los fines representan el objeto principal de una entidad, es el principal motivo de los miembros que la constituyen, es la única razón por la que sus miembros conforman la entidad, y normalmente es donde se encuentra toda la fuerza operativa de la entidad. Los fines de una entidad pueden ser diversos, para un mayor número de personas su expectativa será la búsqueda del lucro personal, mientras que un grupo menor será el bienestar social quienes renuncian a sus expectativas de lucro.

Fernandez Ruiz (2011) refiere:

Son personas jurídicas que carecen de fines de lucro, las que no están animadas por el propósito de obtener una ganancia, sino que pretenden cumplir un cometido social, o bien, tienen por objeto la realización de actividades filantrópicas o altruistas no lucrativas, como las de asistencia social, entre las que se encuadran las fundaciones, las cuales pueden llegar a considerarse en un régimen fiscal de no contribuyentes (p. 243).

Una entidad no lucrativa tiene como principal motivo el logro del bienestar social de sus miembros, para lo cual todas sus operaciones conllevan a atender y resolver sus problemas o necesidades del grupo o de terceros. Los objetivos de los asociados no parten de la búsqueda del enriquecimiento económico, por lo que no esperan beneficiarse de la 
entidad de forma directa ni indirecta, sino más bien sus fines son altruistas, que en muchos casos elevan el espíritu de servicio de sus miembros.

\section{- Definición de las actividades de una entidad no lucrativa}

Respecto a las actividades, la Real Academia Española (2018) define a las actividades como: "Conjunto de operaciones o tareas propias de una persona o entidad"

Las actividades representan las operaciones que realiza una entidad para el logro de sus fines u objetivos, las cuales consistenten en comprar o vender bienes, obtener o prestar servicios, contratar o ser contratado, cobrar o pagar, financiarse o financiar, etc., actividades que no necesariamente son similares a los fines de una entidad no lucrativa, sino más bien estas son el medio que conlleva a cumplir el fin.

En una entidad no lucrativa las actividades corresponden a los medios usados para el logro del fin social, las cuales se espera que estas estén ligadas a los fines; sin embargo, podría darse el caso de que dichas actividades correspondan a operaciones empresariales totalmente diferentes a los fines sociales. En la actualidad, muchas entidades no lucrativas vienen ejerciendo actividades como alquilar sus inmuebles, vender bienes, prestar dinero, invertir en valores, entre otros rubros empresariales, que guardan grandes diferencias con los fines de su constitución.

\section{- Definición de rentas de una entidad no lucrativa}

El diccionario de la Real Academia Española (2018), define a la renta como: "Utilidad o beneficio que rinde anualmente algo, o lo que de ello se cobra".

Las rentas en una entidad corresponden a la utilidad o beneficio obtenidos del desarrollo de sus operaciones. Las entidades no lucrativas al igual que las lucrativas, están en condiciones de obtener utilidades, sin que ello desnaturalice el fin de su constitución. Por lo tanto, bien podrían las entidades no lucrativas acumular grandes cantidades de utilidades según sus estados financieros, sin que ello ponga en riesgo su actuación constitutiva de entidad no lucrativa. Ahora bien, es necesario identificar los tipos de rentas que pueden generar las entidades.

García Mullin (1980) refiere que existen por lo menos tres consideraciones que pueden confluir en el concepto de renta: 
Lo primero deriva de que el concepto de renta tiene originalmente cuño económico; lo segundo es resultado que el impuesto a la renta es visualizado como uno de los más eficientes instrumentos para el financiamiento de los gastos del Estado distribuyendo el peso de la carga entre los habitantes según principios de equidad, en función de sus respectivas capacidades contributivas. Y las consideraciones técnicas tributarias derivan del hecho insoslayable de los conceptos teóricos que se adopten deben concentrarse en definiciones legales susceptibles de ser operadas eficientemente por la administración. (p. 13)

Siguiendo a García Mullin, consideramos que las renta obtenidas por las entidades no lucrativas podría encajar en el concepto de renta desde el aspecto económico, en tanto estas entidades, podrían realizar operaciones económicas que les genere rentas, capaces de contribuir al fisco.

\section{- Definición de lucro de una entidad no lucrativa}

Por lo general el lucro de una entidad no lucrativa está asociada al reparto de las utilidades; sin embargo, existen otras formas de interpretar la definición de lucro, ya sea a través de lo económico o lo social:

\section{- Concepto económico de lucro:}

Según el Diccionario de la Real Academia Española (2018), lucro es: “Ganancia o provecho que se saca de algo".

Como se observa el concepto del lucro consiste en obtener una ganancia o provecho proveniente de una fuente (algo), de la que no necesariamente se demanda la distribución de la ganancia. Es obvio que el solo hecho de rentabilizar (obtener ganancias) configura el concepto de lucrar. Así, por ejemplo, una entidad que adquiere y enajena un bien marginando una rentabilidad, ya obtiene lucro. Ahora bien, el concepto de lucro no solo debe ser vista en cabeza de la entidad, sino también en beneficio de la persona natural propietaria o beneficiaria de dicha entidad, por lo que, en tanto la entidad obtenga utilidades, directamente estaría beneficiando a sus beneficiarios. Esta explicación nos otorga un concepto de lucro económico que va más allá de la clásica definición de distribución directa de utilidades aplicable al tratamiento de las sociedades lucrativas, 
para dar paso a la definición del lucro cuyas utilidades podrían ser consumidas en la misma entidad, ya sea en sus fines o en sus actividades.

\section{- Concepto social de lucro:}

El Diccionario de la Real Academia Española (2018), define la palabra lucrar como: "Conseguir lo que se desea", o "Ganar, sacar provecho de un negocio o encargo".

Aplicando el concepto del Diccionario de la Real Academia, el lucro también significa "conseguir lo que sea desea", deseo que está relacionado con un objetivo que no siempre será un beneficio económico otorgado por la entidad, como por ejemplo el reparto de utilidades, sino más bien que este sea un medio para lograr un objetivo personal. Este provecho no siempre puede ser medido en términos cuantitativos, sino cualitativos, en el que el beneficio podría estar orientado, por ejemplo, en elevar la imagen de una persona que trabaja o lidera en la institución y que, a través de ella o ello obtendría un provecho, que en el futuro le permita un mejor estatus social o político.

\section{- Definición de distribución de beneficios en una entidad no lucrativa}

La definición de distribución de beneficios es un concepto que proviene de las sociedades mercantiles, debido que por naturaleza el reparto de dividendos es un derecho de los socios o accionistas de una sociedad y no de una entidad no lucrativa.

Al respecto Talledo Mazú (2008) cuando se refiere a la distribución de utilidades en la Ley General de Sociedades, manifiesta: "La distribución de utilidades es de derecho fundamental y primordial de todo socio en cualquier tipo de sociedad. Lo es al extremo que la privación de ese derecho a cualquier socio determina la nulidad del contrato social”. (p. 27)

La idea de referir a Talledo no es para encontrar una definición de distribución de utilidades dentro de la Ley General de Sociedades para las entidades no lucrativas, porque tal ordenamiento no es aplicable a las entidades no lucrativas, sin embargo, lo que se busca es encontrar los elementos que configuran para que una entidad incurra en la distribución de utilidades. Por lo que, siguiendo al autor, se puede afirmar que la distribución es derecho fundamental y primordial de los socios de una sociedad lucrativa, al extremo que, de no cumplirse este derecho, se determina la nulidad del contrato social. Mientras que las referidas características no tendrían efecto en las entidades no lucrativas, 
debido que los asociados no cuentan con derechos sobre las utilidades, y por el contrario el acto de distribuir, de inmediato pondría a la entidad en una de tipo empresarial.

Así, por ejemplo, la Ley General de Sociedades en su artículo $230^{\circ}$ establece las reglas para la distribución de dividendos de una sociedad, dentro de las que destaca la regla de distribución de dividendos, pero bajo la condición de la previa existencia de las utilidades.

Para que se realice una distribución de utilidades, primero debe existir la utilidad, la cual se puede verificar en los estados financieros; en segundo lugar, debe realizarse el acuerdo de distribución y; en tercer lugar, debe darse el acto de entrega. Llevado estos componentes al campo de las entidades no lucrativas, podemos encontrar el primer componente de la utilidad, mientras que el segundo componente del acuerdo de distribución de utilidades normalmente no se realiza, por lo menos oficialmente y; por último, el tercer componente de la entrega de la utilidad de forma oficial, por lo general, tampoco se realiza, pero se podría configurar de forma indirecta.

\section{- Definición de exoneración}

Villegas (2001) con relación a la hipótesis de la exoneración señala:

Estos hechos o situaciones que enervan la eficiencia generadora del hecho imponible se denominan 'exenciones y beneficios tributarios'. Tienen la virtud de (a modo de metafórica tijera) poder 'cortar' el nexo normal entre la hipótesis como causa y el mandamiento como consecuencia. En efecto, cuando se configuran exenciones o beneficios tributarios, la realización del hecho imponible ya no se traduce en el mandato de pago que la norma tributaria originalmente previó.

Veamos, entonces: Tenemos una hipótesis legal condicionante tributaria (hecho imponible). Pero no está sola. Está escoltada por una hipótesis legal neutralizante tributaria.

La consecuencia de la primera es el precepto de pagar el exacto monto tributario que la ley ordena.

La consecuencia de la segunda es impedir (total o parcialmente) que la realización de la primera se traduzca en el originario precepto. 
En otras palabras y utilizando didácticamente un idioma metafórico: la hipótesis legal neutralizante tributaria es la enemiga del hecho imponible”. Su misión es la de destruir en forma total o parcial la consecuencia habitual de la realización del hecho imponible". (pp. 281-282).

A partir de lo afirmado por Villegas, se puede rescatar que, si bien las rentas de las entidades no lucrativas atraviesan la puerta de la hipótesis de incidencia, es la exoneración una norma tributaria que, aunque no tiene por objeto retirarla del hecho imponible, sin embargo, extiende un manto sobre el hecho gravado, para protegerla del impuesto.

En el inciso a, del párrafo 23, de la sentencia del Tribunal Constitucional hace una réplica de la definición de exoneración manifestada por del Tribunal Fiscal en la RTF N. 559-4-97, de la forma siguiente:

... el término 'exoneración' se refiere a que, no obstante que la hipótesis de incidencia prevista legalmente se verifica en la realidad, es decir, que se produce el hecho imponible, éste por efectos de una norma legal no da lugar al nacimiento de la obligación tributaria, por razones de carácter objetivo o subjetivo. (Expediente N..$^{\circ}$ 06403-2006-PA/TC).

Siguiendo al Tribunal Constitucional, las exoneraciones atraviesan la hipótesis de incidencia, llegándose a consolidar el hecho imponible, pero por efectos de la norma de exoneración se evita el nacimiento de la obligación tributaria. 


\section{CAPÍTULO II: RÉGIMEN TRIBUTARIO APLICABLE A LAS ENTIDADES SIN FINES DE LUCRO EN EL IMPUESTO A LA RENTA}

La norma peruana que regula el tratamiento del Impuesto a la Renta en el Perú está dada por la Ley del Impuesto a la Renta aprobado mediante Decreto Supremo No 179-2004$\mathrm{EF}$, norma que regula el tratamiento del impuesto a la renta de las entidades no lucrativas que son materia de nuestra investigación.

\subsection{La hipótesis de incidencia del Impuesto a la Renta en las entidades no lucrativas}

Para la presente investigación, lo primero que se analiza es si las operaciones realizadas por las entidades no lucrativas se encuentran dentro del ámbito de aplicación del impuesto, luego, se verificó si estas entidades son sujetos del impuesto, y finalmente cual es el tratamiento otorgado por la legislación respecto a las exoneraciones de estas entidades.

\subsubsection{El ámbito de aplicación}

Respecto al ámbito de aplicación la Ley del Impuesto a la Renta, establece, que el Impuesto a la Renta grava: "Las rentas que provengan del capital, del trabajo y de la aplicación conjunta de ambos factores, entendiéndose como tales aquellas que provengan de una fuente durable y susceptible de generar ingresos periódicos" (Texto Único Ordenado de la Ley del Impuesto a la Renta, 2004, inciso a, art. 1)

En este inciso, la legislación tributaria, al describir la renta producto como renta gravada, lo que busca es gravar las rentas que nacen de la combinación de las rentas de capital más las rentas de trabajo, que para el caso de las entidades no lucrativas le aplicaría cabalmente, toda vez que estas organizaciones generan rentas combinadas de capital más trabajo, conocidas como rentas empresariales. Por lo tanto, si bien el término de rentas empresariales está asociado con las entidades lucrativas; sin embargo, también aplica para la calificación de las rentas de entidades no lucrativas. 


\subsubsection{De los contribuyentes}

De acuerdo a la Ley del Impuesto a la Renta, se establece:

Son contribuyentes del impuesto las personas naturales, las sucesiones indivisas, las asociaciones de hecho de profesionales y similares y las personas jurídicas. También se consideran contribuyentes a las sociedades conyugales que ejercieran la opción prevista en el artículo $16^{\circ}$ de esta ley (Texto Único Ordenado de la Ley del Impuesto a la Renta, 2004, art. 14).

La norma analizada entre otros sujetos, considera como contribuyentes del impuesto a las personas jurídicas, por lo que las asociaciones al gozar de personalidad jurídica, preliminarmente se puede concluir que forman parte del universo de contribuyentes para el impuesto a la renta. De no haber existido mayor legislación tributaria, se podría concluir que las asociaciones son contribuyentes del impuesto, aun cuando sus rentas la destinen a fines no lucrativos; por lo que es necesario seguir revisando la legislación para encontrar algún desgravamen como la inafectación, exoneración, beneficio o incentivo tributario, que la libere o reduzca del pago del impuesto.

\subsection{De los sujetos e ingresos inafectos}

Ahora bien, la Ley del Impuesto a la Renta ha exceptuado del impuesto a dos grupos de beneficiados: un grupo corresponde a sujetos y el otro a los ingresos; liberándolos de forma indefinida del impuesto en la modalidad de inafectación. Esta desgravación se encuentra en el artículo $18^{\circ}$ de la Ley que, desde nuestro análisis, tiene dos partes:

Un primer grupo, se encuentra en el artículo $18^{\circ}$ de la Ley del Impuesto a la Renta, donde se considera sujetos inafectos a las siguientes entidades:

No son sujetos pasivos del impuesto:

a) El Sector Público nacional, con excepción de las empresas conformantes de la actividad empresarial del Estado.

b) Derogado.

c) Las fundaciones legalmente establecidas (...)

d) Las entidades de auxilio mutuo. 
e) Las comunidades campesinas.

f) Las comunidades nativas. Ley (Texto Único Ordenado de la Ley del Impuesto a la Renta, 2004, art. 14).

Las entidades comprendidas en los incisos c) y d) de este artículo, deberán solicitar su inscripción en la SUNAT, de acuerdo a las normas que establezca el Reglamento.”

En este primer grupo la Ley taxativamente ha otorgado la inafectación a cinco (05) tipos de entidades, sin considerar a las entidades estatales, cuatro (04) de ellas corresponden a entidades civiles privadas, de las cuales ninguna corresponde a las entidades sin fines de lucro que son materia de nuestra investigación. Al revisar las entidades beneficiadas de la inafectación, claramente se puede dar cuenta de que el Estado ha querido beneficiar solo a un grupo limitado de entidades, las cuales, a todas luces, son entidades cuyos fines son íntegramente de ayuda social y, por lo general, estas no desarrollan actividades empresariales.

En un segundo grupo, el artículo $18^{\circ}$ esta vez ha establecido inafectaciones a los ingresos, de los cuales podemos mencionar:

Primero, de los ocho tipos de ingresos que gozan del privilegio de la inafectación, los seis primeros corresponden estrictamente a ingresos de personas naturales y los dos últimos por productos financieros; pero ninguno tiene relación con la inafectación del impuesto a la renta de una entidad, lo que demuestra que el legislador fue cuidadoso en no otorgar la inafectación a todas las entidades no lucrativas, restringiendo a un gran universo de las entidades como las de este trabajo de investigación.

Segundo, la Ley del Impuesto a la Renta tampoco ha otorgado la inafectación para los ingresos provenientes de las entidades sin fines de lucro materia de este trabajo de investigación.

Por lo tanto, considerando que la Ley del Impuesto a la Renta no ha inafectado a las entidades sin fines de lucro ni a sus ingresos, será necesario revisar las normas de exoneración otorgadas en la Ley. 


\subsection{La exoneración de las entidades sin fines de lucro}

\subsubsection{Normas establecidas en la Ley del Impuesto a la Renta}

La Ley del Impuesto a la Renta establece que están exonerados del Impuesto, el cual de acuerdo a la Ley No 30899 fue prorrogado hasta exoneración hasta el 31.12.2019, lo siguiente:

Las rentas de fundaciones afectas y de asociaciones sin fines de lucro cuyo instrumento de constitución comprenda exclusivamente, alguno o varios de los siguientes fines: beneficencia, asistencia social, educación, cultural, científica, artística, literaria, deportiva, política, gremiales, y/o de vivienda; siempre que destinen sus rentas a sus fines específicos en el país; no las distribuyan, directa o indirectamente, entre los asociados o partes vinculadas a estos o a aquellos, y que en sus estatutos esté previsto que su patrimonio se destinará, en el caso de disolución, a cualquiera de los fines contemplados en este inciso (Texto Único Ordenado de la Ley del Impuesto a la Renta, 2004, art. 19).

Ahora bien, mediante el artículo $3^{\circ}$ del Decreto Legislativo $\mathrm{N}^{\circ} 1120$ se introdujo disposiciones anti elusivas que modificaron el inciso b) del referido artículo $19^{\circ}$, incorporando nuevas consideraciones para la calificación del concepto de distribución indirecta de las rentas, pero no expresa nada respecto a los otros tres requisitos para gozar la exoneración.

\subsubsection{Consideraciones establecidas en el Reglamento de la Ley del Impuesto a la} Renta

En una lectura del artículo $8^{\circ}$ del Reglamento del Impuesto a la Renta en el que se establece los requisitos para gozar de la inafectación y de la exoneración, respecto al inciso b) del artículo $19^{\circ}$ de la Ley, el reglamento aborda solo dos aspectos: Reglamenta sobre los requisitos para la inscripción de la entidad, y presenta consideraciones para la calificación de vinculación que conlleva al requisito de la no distribución directa e indirecta de utilidades, sin embargo, respecto a los demás requisitos no hace ninguna referencia. 


\subsection{Requisitos sustanciales para gozar de la exoneración}

La Ley del Impuesto a la Renta en el inciso b) del artículo $19^{\circ}$ deja establecido que las rentas de las entidades no lucrativas se encuentran exoneradas siempre que cumplan los siguientes requisitos:

$1^{\circ}$ Que su instrumento de constitución corresponda exclusivamente a uno o más de los fines establecidos en el inciso b) del artículo $19^{\circ}$ de la Ley.

$2^{\circ}$ Que sus rentas se destinen a los fines específicos en el país.

$3^{\circ}$ Que sus rentas no se distribuyan de forma directa ni indirecta.

$4^{\circ}$ Que en su estatuto se establezca que en el caso de una disolución el destino del patrimonio será destinado a un fin semejante a los descritos en la Ley.

\subsubsection{Los fines sujetos a la exoneración}

El primer requisito que la Ley ha precisado para el goce de la exoneración es que el testimonio de una entidad no lucrativa debe exclusivamente contener alguno o varios de los fines que la Ley del Impuesto a la Renta ha habilitado. La precisión pareciera poco relevante; sin embargo, la delimitación expresada en el término "exclusivamente" es trascendente debido que se ha preocupado en excluir a cualquier otro tipo de finalidad que no sea la nombrada en la norma. Esta delimitación no es optativa para la entidad, por lo que su instrumento de constitución debe estar limpia de cualquier fin que la norma tributaria no haya concedido, aun cuando dichos fines para todo análisis persigan elevados objetivos de desarrollo social, y que el solo hecho de contener el Estatuto un fin no permitido lo excluiría del beneficio de la exoneración. En este sentido, los únicos fines que debe contener un Testimonio para el goce de la exoneración son: 1) Beneficencia, 2) asistencia social, 3) educación, 4) cultural, 5) científica, 6) artística, 7) literal, 8) deportiva, 9) política, 10) gremiales, y/o 11) vivienda.

En recientes resoluciones como la RTF No 2908-1-2017, RTF No 1637-10-2017, RTF No 1386-5-2017, RTF No 1903-2-2017, entre otras, el Tribunal Fiscal ha resuelto que para dar cumplimiento del requisito "que el instrumento de constitución comprenda exclusivamente", se demanda que el Estatuto de la entidad no lucrativa contenga exclusivamente los fines establecidos en la Ley. Agregan las resoluciones que en los 
Estatutos no pueden incorporarse fines distintos, tampoco fines amplios, ni fines ambiguos; que difieran de los permitidos.

Sobre el mismo análisis de la exclusividad, la delimitación dispuesta por el legislador, en el campo operativo facilita en gran medida al control tributario, debido que, en ausencia de tales delimitaciones, las entidades no lucrativas podrían desarrollar fines permitidos y no permitidos por la Ley, lo que generaría un problema para determinar la cuantía de la renta destinada a los fines permitidos y la proporción de los admitidos. Ahora bien, si bien la Ley del Impuesto a la Renta ha habilitado solo once fines que gozan de la exoneración, las entidades por decisión de sus miembros no están prohibidas civilmente de desarrollar otros fines diferentes, sin embargo, esta decisión pondría en riesgo el beneficio de la exoneración, tanto de las rentas provenientes de los fines no habilitados, como los que provengan de fines no aceptados.

\subsubsection{El destino de la renta}

El segundo requisito para acceder a la exoneración del impuesto del inciso b) del artículo $19^{\circ}$ de la Ley, consiste en que las entidades sin fines lucrativos destinen sus rentas a los fines establecidos en el país. Este requisito aparentemente es uno de los más fáciles de entender y de cumplir; sin embargo, es el que más controversias contiene al momento de su aplicación y es donde se centra la investigación.

Este requisito nos conlleva a los siguientes comentarios:

La Ley establece que las rentas se destinen a los fines, por lo que se podría entender que las rentas generadas por la entidad en un ejercicio tienen un solo destino, y ese único destino es el fin de la entidad no lucrativa, sin dejar posibilidad de que los fondos sean entregados a actividades empresariales intrínsecas a la entidad, aun cuando estas actividades sean un medio para conseguir fondos para el cumplimiento del fin.

La Ley ha puesto como requisito para la exoneración que las rentas sean destinadas al fin, de lo contrario se entiende que las rentas estarían gravadas con el impuesto, sin establecer un plazo para el cumplimiento del destino, de lo cual se podría pensar que la renta generada de un ejercicio al momento de su declaración ya debería estar destinada al fin, o en contraposición se podría sostener que la Ley no ha establecido un plazo para realizar el destino. 
La Ley, con este requisito, ha establecido que la renta sea destinada al fin; sin embargo, la norma no ha establecido un monto o cuantía, por lo cual se podría asumir que el destino debe ser por el total de la renta o bastaría que la asociación destine algo de la renta para que se dé por cumplido el requisito.

\subsubsection{La no disposición directa ni indirecta de las rentas}

El tercer requisito para acceder a la exoneración del impuesto de acuerdo al inciso b) del Artículo $19^{\circ}$ de la Ley es uno de los más conocidos y el legislador se ha preocupado en regular con mayor precisión, tratando de prohibir todas las modalidades de distribución de las rentas de la asociación, para lo cual la ley ha normado en tres aspectos:

1. La ley prevé la prohibición de cualquier forma de distribución de utilidades (directas o indirectas) a sus asociados o partes vinculadas, estableciendo bases del concepto de vinculación y otorgando al reglamento la facultad de emitir los supuestos para la configuración de la vinculación. Para esto, la ley refiere a tres casos de vinculación: Primero, la participación en la administración, control o aporte significativo al patrimonio; segundo, la vinculación con los parentescos y; tercero, la utilización de personas interpuestas.

2. La norma crea conceptos especiales de distribución indirecta, estableciendo dos modalidades cuando el costo o gasto incurrido por la asociación califica como distribución indirecta a sus asociados o partes vinculadas a estos o aquéllos. Para ello, la Ley considera como distribución indirecta, cuando existen dos supuestos: Primero, si los costos o gastos no son necesarios para el desarrollo de sus actividades o que no sean razonables en relación con sus ingresos y, segundo, que estos costos o gastos resulten sobrevaluados.

3. La ley precisa dos hechos más que califican la vinculación: El primero está orientado a la entrega de dinero o bienes no susceptible de posterior control tributario y, el segundo, a la restricción del uso de los bienes de la asociación en actividades diferentes a los fines de la misma. Se agrega que el Reglamento establecerá cuales son los costos susceptibles de posterior control tributario. 


\subsubsection{La contemplación del destino del patrimonio en caso de disolución}

El cuarto requisito para acceder a la exoneración del impuesto, de acuerdo al inciso b del Artículo $19^{\circ}$ de la Ley, consiste en que la asociación, desde su constitución, contemple cual será el destino de todo el patrimonio acumulado si en algún momento se disuelve la asociación. Con este requisito, el legislador se asegura de que todas las rentas generadas que se ven expresadas en los activos de la entidad, finalmente no sean de ninguna forma distribuibles entre sus asociados y vinculados, sino que estos bienes se sigan explotando en organizaciones no lucrativas que desarrollen fines que el Estado ha elegido.

Este requisito tiene como propósito evitar que la renta que no fue destinada a los fines y se encuentra acumulada en el patrimonio, la cual gozó de la exoneración del impuesto, finalmente no termine siendo asignada a sus asociados o terceros, por lo cual la legislación correctamente se antepone a cualquier planeamiento tributario, decretando que tales rentas continúen en las arcas de entidades con fines similares a la entidad que las obtuvo. 


\section{CAPÍTULO III: CONTROVERSIAS EN MATERIA DEL TRATAMIENTO DEL IMPUESTO A LA RENTA DE LAS ENTIDADES SIN FINES DE LUCRO}

En este capítulo se abordan las controversias que existen entre el requisito "destino de la renta para sus fines específicos en el país" establecido en el inciso b) del artículo $19^{\circ}$ de la Ley del Impuesto a la Renta y su cumplimiento para gozar de la exoneración. Esta controversia se presenta, porque en la actualidad las entidades no lucrativas vienen derivando fondos a actividades empresariales, los cuales en muchas oportunidades retornan sin beneficios y en otros casos nunca retornan, eludiendo el destino al cual corresponde según los fines de la sociedad.

\subsection{Controversia respecto al instrumento de constitución: Fines o actividades empresariales que realizan las Entidades Sin Fines de Lucro}

Los conceptos de fines y actividades siempre han sido materia de confusión al momento de aplicar la legislación tributaria en el desarrollo de las operaciones de las entidades no lucrativas, creando dos posiciones. Una posición radical, es que tales entidades no pueden realizar ninguna actividad diferente a los fines que la norma tributaria ha facultado, mientras que la segunda posición sustenta que está permitido realizar cualquier actividad, más allá de los fines enumerados en la Ley, siempre que el resultado de dichas actividades regrese a la entidad para el cumplimiento de sus fines. Si la primera posición fuera la correcta, se agotarían los temas de discusión; sin embargo, si la segunda posición fuera la correcta, se generarían nuevas controversias como determinar cuál es el límite, hasta cuánto pueden las entidades no lucrativas realizar actividades empresariales; así como, por cuánto tiempo pueden permanecer las rentas fomentando las actividades empresariales.

\subsubsection{Los fines de la entidad}

- El fin social 
La Ley del Impuesto a la Renta en el inciso b) del artículo $19^{\circ}$, ha establecido una relación de fines aceptados para el goce de la exoneración, si bien con ello no se obtiene una definición propia de los fines; sin embargo, permite identificar una característica homogénea que está vinculada con el aspecto social de los fines. De la revisión de los fines habilitados en la Ley, se encuentra que casi todos están vinculados con fines sociales, aunque algunos de ellos como el de beneficencia, asistencia social, cultural, científica, literaria, política y gremial; podrían estar más vinculados con fines altruistas y ser ajenas al ámbito empresarial, mientras que otros fines como la educación, el arte, el deporte y de vivienda podrían, en el transcurso de sus operaciones, vincularse con actividades ajenas a las altruistas y sociales.

Los fines que conllevan a la exoneración normalmente nacen de la política fiscal del Estado, no solo por el hecho de beneficiar a un sector o institución, sino porque el Estado pretende llegar a los sectores elegidos de una manera más rápida y oportuna, usando como aliados a las entidades no lucrativas para su logro. El Estado, al despojarse de su facultad recaudadora, entiende que deja de percibir el impuesto de una operación que siendo gravada optó por exonerarla, pero realmente nunca llega a despojarse, porque diligentemente vigila el impuesto encargado a las entidades no lucrativas. Por estas razones, el Estado, recurriendo a su potestad tributaria, emite normas que le aseguran el correcto destino de los impuestos, en este caso, en la Ley del Impuesto a la Renta ha establecido los únicos fines a los cuales las entidades no lucrativas deben destinar el impuesto no pagado.

\section{- Controversia de la exclusividad del fin}

Ahora bien, de acuerdo a la Ley del Impuesto a la Renta se ha establecido que los fines de las entidades deberán ser exclusivamente los contemplados en dicha Ley, por lo que, en el caso de que la entidad habilite en su Estatuto un fin distinto a lo establecido, de inmediato los fines de la entidad perderían la exclusividad requerida. En este escenario, por lo menos se presentan dos problemas respecto a la exclusividad de los fines:

Primero, para el caso de las instituciones que se constituyeron antes de la vigencia de la Ley del Impuesto a la Renta, debería de ser aceptada la presencia de algunos fines diferentes a los establecidos en la Ley, toda vez que al momento de su formalización no 
contaban con tal regulación. Mal se haría en desestimar la exoneración de las entidades cuyo instrumento de constitución no contemple exactamente los fines establecidos en la Ley, en el supuesto que solo desarrollen fines habilitados en la Ley.

Segundo, las entidades jurídicamente pueden constituirse con fines sociales diferentes a los establecidos en la Ley fiscal, por lo que bien podrían desarrollar fines al margen de no contar con la exoneración y, a la vez, desarrollar fines habilitados que gocen de la exoneración. Sin embargo, de acuerdo a la actual legislación fiscal, las entidades no lucrativas para efectos de gozar de la exoneración están prohibidas de perseguir fines no contemplados, obligándoseles a renunciar a algunos fines a efectos de no perder toda la exoneración.

En conclusión, respecto a los fines de las entidades no lucrativas, si bien pueden existir divergencias en su definición y exclusividad, estas quedan resueltas, en tanto el legislador, ejerciendo su potestad tributaria, ha otorgado su propia definición, plasmada en un listado de fines, únicos e irreemplazables que, para gozar de la exoneración, las entidades deben dedicarse exclusivamente a uno o varios de estos, sin la posibilidad de desarrollar otro, por más que, a todas luces, pueda considerarse como un fin altruista o de bienestar social.

\subsubsection{La permisividad de las actividades comerciales}

\section{- La permisividad de la Ley del Impuesto a la Renta}

La Ley del Impuesto a la Renta no ha prohibido el desarrollo de actividades empresariales en las entidades no lucrativas, lo que ha restringido es que las utilidades generadas de tales actividades sean destinadas a fines no previstos en la Ley. Las razones de la permisividad se pueden enfocar básicamente desde dos ámbitos: El económico y el legal.

Desde la perspectiva económica se asevera que, si las utilidades generadas por las entidades no lucrativas no son distribuidas y el único destino de estas son para el cumplimiento del fin social, entonces es un error que la norma tributaria prohíba el desarrollo de las actividades empresariales que tienen como función la generación de rentas para la entidad. Mientras que, desde el ámbito legal, la Ley, al establecer los requisitos para gozar de la exoneración, solo exige que las rentas se destinen al fin social, 
mas no observa la forma de obtener las rentas, por lo tanto se deja habilitada cualquier forma de realización de actividades comerciales.

En concordancia con nuestra posición, Belaunde y Parodi (1998), al referirse al marco legal del sector privado sin fines de lucro en el Perú, manifiesta:

En este sentido, el carácter no lucrativo de una organización no impide la realización de actividades mercantiles, las cuales pueden tener vinculación directa con su objeto social (así, por ejemplo, realizar labores de comercialización de los productos de la población beneficiaria de proyectos de una ONG, tareas de asistencia crediticia, entre otras) o indirecta, es decir, destinadas a la generación de recursos propios a fin de permitir su funcionamiento (prestación de asesorías remuneradas, eventos y conferencias, entre otras) (p. 27).

Por su parte Vega (2012) al desarrollar el derecho de asociación, manifiesta:

...en verdad, la no lucratividad de una asociación, de una fundación o de cualquier otra organización está dada por la circunstancia de que los ingresos que obtenga del más variado tipo de actividades que realicen no se distribuyan entre los miembros y/o administradores de ellas. Las utilidades se deben aplicar a los fines institucionales para lograr su consecución. En otros términos, tales organizaciones si pueden realizar todas las actividades económicas que les permita contar con fondos para satisfacer ampliamente sus fines, sin distribuir sus dividendos entre quienes sean parte o se hagan hacen cargo de ellas". ( p. 249).

Por su parte, Gallegos (2016) al desarrollar el tema del tratamiento tributario de las asociaciones civiles sin fines de lucro, manifiesta:

Por ello, desde el punto de vista tributario, las asociaciones nada les impide realizar operaciones empresariales, basta que estén dentro de la hipótesis de incidencia de la norma tributaria, realicen actividades como generadores de renta de tercera categoría para que sean sujetos de impuestos. (p. 15)

A partir de lo afirmado por Belaunde y Parodi, Vega y Gallegos, se coincide con la permisividad de las actividades empresariales desarrolladas por las entidades sin fines de lucro, siempre que las rentas generadas por las actividades empresariales se retribuyan a los fines sociales; sin embargo, a diferencia de lo manifestado por Belaunde y Parodi, 
consideramos que las actividades empresariales no necesariamente deben estar vinculadas con el objeto social, sino que la entidad puede realizar incluso actividades aisladas al fin social. Mantenemos esta posición porque entendemos que finalmente todas las rentas generadas, provenientes de cualquier actividad (vinculadas al fin o no), no son distribuidas, más bien por el contrario, son destinadas al fin, por lo que mal se haría en limitar las actividades que no son intrínsecas o directamente vinculadas al desarrollo del fin social.

\section{- La posición del Tribunal fiscal acerca de la permisividad}

La jurisprudencia hace más de dos décadas ya había tomado posición sobre la controversia de la permisividad de las actividades empresariales. Así el Tribunal Fiscal refiere lo siguiente:

En este sentido se ha demostrado que el desarrollo de actividades mercantiles no es una finalidad de la asociación sino uno de los mecanismos que pueden usar las asociaciones civiles en las que COINCIDE participe para obtener fondos para el cumplimiento de los fines institucionales de cada una de ellas. (Expediente N. ${ }^{\circ}$ 246-95, 1997)

Asimismo, respecto a la pérdida de la exoneración por el desarrollo de las actividades comerciales, el Tribunal Fiscal resuelve lo siguiente:

... la Ley del Impuesto a la Renta, no gravan las rentas de las asociaciones, por no tener éstas fines de lucro y en la medida que sus ingresos no sean destinados a fines distintos a los de su institución, lo cual significa que la exoneración no está en función a una de las actividades que realiza para cumplir sus objetivos. Expediente N. $\left.{ }^{\circ} 10904-94,1998\right)$

En lo referente a las mencionadas resoluciones y otras similares como la RTF $\mathrm{N}^{\mathrm{o}}$ 01511-3-2003, coincidimos con la posición del Tribunal Fiscal respecto a que una entidad no lucrativa puede desarrollar una actividad empresarial, siempre que el beneficio obtenido de ella sea redimido por los fines de la entidad y que a la vez coincidan con los establecidos en la Ley del Impuesto a la Renta.

\section{- Los efectos de la permisividad}


Así pues, en medio de esta permisividad otorgada por la Ley del Impuesto a la Renta y las jurisprudencias del Tribunal Fiscal, en los últimos años, muchas de estas entidades han dado rienda suelta al desarrollo de actividades empresariales, muchas de ellas con una evidente planificación tributaria, la constante de todas viene siendo derivar los fondos de la entidad a las actividades empresariales, con el pretexto de que dichas actividades generarán rentas que luego retornarán a los fines de la institución.

En la siguiente tabla se puede apreciar una muestra selectiva de las entidades no lucrativas. Además, se observa que el fisco, entre el 2015 y 2018, recaudó por Impuesto General a las Ventas - IGV, los siguientes montos en soles:

Tabla 3.1

Ingreso Anual recaudados. Tributos Internos por actividad económica y tributo

\begin{tabular}{|c|c|c|c|c|c|}
\hline CIIU & DESCRIPCIÓN & 2018 & 2017 & 2016 & 2015 \\
\hline 8010 & $\begin{array}{l}\text { ENSEÑANZA } \\
\text { PRIMARIA }\end{array}$ & $1,463,829.00$ & $1,224,356.00$ & $1,197,544.00$ & $1,250,777.00$ \\
\hline 8021 & $\begin{array}{l}\text { ENSEÑANZA } \\
\text { SECUNDARIA } \\
\text { FORMACION GRAL } \\
\end{array}$ & $2,694,019.00$ & $2,815,031.50$ & $2,185,234.00$ & $1,842,581.00$ \\
\hline 8022 & $\begin{array}{l}\text { ENSEÑANZA } \\
\text { SECUNDARIA } \\
\text { FORMAC. TECNICA } \\
\end{array}$ & $440,178.00$ & $244,134.00$ & $352,684.00$ & $201,090.00$ \\
\hline 8030 & $\begin{array}{l}\text { ENSEÑANZA } \\
\text { SUPERIOR }\end{array}$ & $92,424,355.81$ & $91,066,080.86$ & $89,637,185.17$ & $88,144,269.35$ \\
\hline 8090 & \begin{tabular}{|l} 
EDUCACIÓN DE \\
ADULTOS Y OTROS \\
\end{tabular} & $18,416,810.10$ & $15,932,224.45$ & $14,575,077.00$ & $11,522,339.00$ \\
\hline 9112 & $\begin{array}{l}\text { ACTIV. } \\
\text { ORGANIZACIONES } \\
\text { PROFESIONALES } \\
\end{array}$ & $13,137,384.00$ & $13,039,960.00$ & $11,379,185.00$ & $10,637,153.00$ \\
\hline 9120 & $\begin{array}{l}\text { ACTIVIDADES DE } \\
\text { SINDICATOS } \\
\end{array}$ & $442,120.00$ & $256,146.00$ & $247,621.00$ & $443,886.00$ \\
\hline 9191 & $\begin{array}{l}\text { ACTIV. } \\
\text { ORGANIZACIONES } \\
\text { RELIGIOSAS } \\
\end{array}$ & $4,757,714.00$ & $4,586,090.00$ & $6,830,119.00$ & $5,013,168.00$ \\
\hline 9192 & $\begin{array}{l}\text { ACTIV. } \\
\text { ORGANIZACIONES } \\
\text { POLÍTICAS } \\
\end{array}$ & $35,665.00$ & $86,614.00$ & $474,297.00$ & $1,027.00$ \\
\hline 9199 & $\begin{array}{l}\text { ACTIVIDADES } \\
\text { OTRAS } \\
\text { ASOCIACION. NCP. }\end{array}$ & $114,156,604.92$ & $107,222,462.00$ & $99,692,991.00$ & $91,762,730.00$ \\
\hline 9232 & $\begin{array}{l}\text { ACTIV. MUSEOS Y } \\
\text { LUGARES } \\
\text { HISTORICOS } \\
\end{array}$ & $2,008,021.00$ & $1,737,522.00$ & $1,667,946.00$ & $1,648,928.00$ \\
\hline 9241 & $\begin{array}{l}\text { ACTIVIDADES } \\
\text { DEPORTIVAS }\end{array}$ & $69,805,642.00$ & $64,370,398.00$ & $47,044,847.00$ & $36,892,857.69$ \\
\hline 9900 & $\begin{array}{l}\text { ORGANIZACIONES } \\
\text { INTERNACIONALE } \\
\mathrm{S} \\
\end{array}$ & $858,745.00$ & $750,803.00$ & $976,436.00$ & $1,836,439.00$ \\
\hline & TOTALES EN S/ & $320,641,087.83$ & $\mathbf{3 0 3}, 331, \mathbf{8 2 1 . 8 1}$ & $276,261,166.17$ & $251,197,245.04$ \\
\hline
\end{tabular}

Fuente: Superintendencia Nacional de Aduanas y de Administración Tributaria, SUNAT (2018). 
Si bien podrían considerarse otras variables, del cuadro estadístico podemos verificar que, del grupo de entidades no lucrativas seleccionadas, la SUNAT entre el 2015 y 2018 tuvo un incremento en la recaudación del 21.66\% respecto al Impuesto General a las Ventas - IGV (De 251,1 millones de soles en el 2015 a 320,6 millones en el 2018), aún cuando el crecimiento global de la recaudación en este periodo solo creció en $15.00 \%$ (77, 307,6 millones en el 2015 a 90,956,3 en el 2018). Este indicador nos puede llevar a concluir que el grupo de entidades no lucrativas en solo el año 2018 pagaron 320, 6 millones de soles a la SUNAT, que nos advierten que dichas instituciones durante este ejercicio desarrollaron operaciones gravadas con el IGV, y que de un rápido enlace entre la Ley del IGV y del Impuesto a la Renta, en tanto las operaciones vinculadas al desarrollo de los fines de las entidades no lucrativas no se encuentran dentro del ámbito de aplicación del Impuesto General a las ventas, nos hace deducir que las operaciones que dieron origen al pago del IGV provienen de actividades empresariales que estas entidades han desarrollado.

Estos datos estadísticos demuestran que en los últimos años se viene incrementando el desarrollo de actividades empresariales en cabeza de las entidades no lucrativas, que a mayor información estadística se seguiría demostrando el incremento. Sin embargo, en nuestra posición la presencia de estas actividades en sí no es el problema de controversia, porque a mayor actividad empresarial, mayor serían los fondos obtenidos para el cumplimiento de los fines, mas bien, el problema se manifiesta porque el objetivo de dichas actividades no siempre es generar rentas para el fin, porque estas prácticas obedecen a una planificación tributaria que busca beneficiar a los asociados o terceros, y la renta finalmente no retorna al fin de la entidad. Es por esta razón que debemos de respondernos: ¿De dónde provienen los fondos para dicho incremento?, ¿Cuánto representa dichos fondos para la entidad?, ¿Por cuánto tiempo permanecen dichos recursos en las actividades empresariales?, ¿Están retornando los beneficios generados por las actividades a los fines de la entidad?; estas son interrogantes que nos llevan a analizar el destino de las rentas de las entidades no lucrativas que abordamos a continuación.

\subsection{Controversia respecto al concepto del destino de las rentas}

De acuerdo al estudio de la Ley del Impuesto a la Renta desarrollada en el Capítulo II verificamos que la norma tributaria ha otorgado la exoneración del pago del 
impuesto a las rentas de las entidades no lucrativas. Sin embargo, un tema de controversia que nos ocupa es respecto a la ausencia de la definición del requisito del destino de la renta a sus fines específicos en el país, establecido en el inciso b de la referida Ley.

El inciso b) del citado artículo dispone un requerimiento de tipo condicional, que exige las rentas sean destinadas a los fines de la entidad, en el entendido que estos fines deben coincidir con los que la Ley ha habilitado. La norma demanda que las rentas se destinen a los fines establecidos mas no ha definido en que consiste el acto de destinar la renta, generándose por lo menos cuatro controversias:

1. Si es posible destinar las rentas a las actividades empresariales o estrictamente debe de ser destinada al fin.

2. Si el concepto de la renta incluye a todos los fondos patrimoniales de la entidad o es que la limitación no alcanza a los aportes.

3. Si existe un porcentaje mínimo por destinar a los fines o es que el $100 \%$ puede ser destinado a una actividad empresarial, y

4. Si existe un plazo para destinar las rentas a los fines o es que estas pueden permanecer sin límite de tiempo en las actividades empresariales.

\subsubsection{El destino de la renta}

La Ley del Impuesto a la Renta establece como requisito para gozar la exoneración, que la renta sea destinada al fin de la entidad, presentándose dos posiciones:

Una primera posición sería, bajo una interpretación literal de la norma se podría entender que, para gozar del beneficio de la exoneración, las rentas obtenidas deben de tener como único destino el fin social de la entidad, sin la posibilidad que dichas rentas se entreguen a fines diferentes, y menos aún a actividades empresariales, por más que dichas actividades sean medios que generen rentas para el fin. Sin embargo, esta posición podría tener un serio cuestionamiento.

En respaldo a esta posición el Tribunal Fiscal resolvió de la siguiente forma:

De lo expuesto, se tiene que la recurrente realizó en el ejercicio 2002 un préstamo a favor de la señora Yolanda Morales Ubillus, lo que acredita que ésta no cumplió con el requisito de destinar sus rentas a sus fines específicos en el país, establecido en el inciso b) del artículo $19^{\circ}$ de la Ley del Impuesto a la Renta, en tal sentido, 
las rentas generadas por aquélla durante el ejercicio 2002 constituyen rentas gravadas con Impuesto a la Renta, correspondiendo en tal sentido declarar infundada la apelación en este extremo. (Expediente N. ${ }^{\circ} 06188-4-2014,2014$ )

En nuestra posición, teniendo en cuenta que la operación de préstamo corresponde a una actividad empresarial, consideramos que el Tribunal Fiscal al resolver este caso, no consideró las diversas resoluciones donde ella había admitido el desarrollo de actividades comerciales ejecutadas por las entidades no lucrativas. En un mayor análisis, podríamos corroborar que en esencia un préstamo otorgado es una operación empresarial que no debería ser calificada como destino de la renta, debido que el acto de prestar no afecta la renta de la entidad, en tanto la operación financiera de prestar solo consiste en el acto de entregar un activo (dinero) y a cambio se recibe otro activo (cuenta por cobrar), en consecuencia la renta de la entidad no se ve afectada, por lo contrario, se espera que ella recupere la inversión, incluso con márgenes de rentabilidad que finalmente servirían para cumplir el fin social.

Si se acepta la posición restrictiva que las rentas sean destinadas exclusiva y directamente a los fines, se estaría quitando la posibilidad que las rentas empresariales financien a los fines, y como resultado la entidad dejaría de obtener mayores beneficios para sus fines, dejándolas solo con ingresos provenientes de los fondos sociales como las donaciones, aportes, cuotas, entre otros similares. Con esta posición prácticamente se estaría suprimiendo el desarrollo de actividades empresariales dentro de una entidad no lucrativa, que incluso podría afectarse a actividades básicas como arrendar un activo ocioso de la sociedad, como por ejemplo el alquiler de los inmuebles ociosos no usados en las horas nocturnas o fines de semana.

Una segunda posición sería que el requisito para gozar de la exoneración denominado destino de la renta, no necesariamente demanda que las rentas sean directamente destinas al fin de la entidad, sino que existe la posibilidad que dichas rentas se inviertan en actividades empresariales, con el objetivo de que dichas actividades generen rentas para el fin. Sin embargo, esta posición también podría generar serias controversias.

Si se considera que la definición de destino de la renta permite que las entidades entreguen sus rentas a las actividades empresariales podrían generarse las siguientes contingencias: 
1. Las entidades podrían destinar el total de las rentas a las actividades empresariales y dejarían sin fondos para los fines, $\mathrm{y}$

2. Las entidades podrían destinar las rentas a las actividades empresariales por un tiempo indeterminado y los fondos no retornarían al fin.

En nuestra posición, aún considerando la presencia de las referidas controversias, consideramos que la segunda posición es la correcta, por las siguientes razones:

1. Las actividades empresariales dentro de una entidad no lucrativa, no contravienen con los fines sociales de la entidad.

2. Las actividades empresariales son generadoras de renta que contribuyen al cumplimiento del fin social de la entidad.

3. Las rentas obtenidas por el desarrollo de actividades empresariales no se distribuyen a los asociados, por lo tanto, no se configura el lucro.

4. Las rentas que la entidad entrega a sus actividades empresariales no deben ser consideradas como destino de la renta, toda vez que dicha entrega debe retornar a la entidad, y con un margen de rendimiento.

En este sentido, somos de la posición que las entidades no lucrativas si pueden destinar sus rentas a las actividades empresariales, sin embargo, es necesario establecer medidas correctivas para resolver las contingencias enumeradas producto de esta permisividad, tema que más adelante desarrollamos. Para ello, primero es necesario analizar las controversias más relevantes que se genera como resultado de dicha permisión, que a continuación son abordados.

\subsubsection{Renta o patrimonio}

La Ley del Impuesto a la Renta refiere que las rentas se destinen al fin, de lo contrario la entidad no goza de la exoneración, pero existe controversia si el concepto de destinar la renta incluye solo a la Renta Neta Imponible o es que esta alcanza a todos los fondos patrimoniales de la entidad, incluido los aportes de los asociados.

Sostener la primera posición, que el requisito alcanza solo a la Renta Neta Imponible, afirmaría que el requerimiento del destino de la renta incluye solo al monto 
de la renta del ejercicio obtenida por la entidad en el ejercicio de sus operaciones, mas no debería cuestionarse los casos cuando se dispongan de los aportes de los asociados. Mientras que la segunda posición conllevaría a sostener que las rentas no solo incluyen a la renta del ejercicio, sino también a los aportes, por lo tanto, ningún activo de la entidad podría destinarse a otros que no sean los fines de la sociedad, de lo contrario se incurría en causal de pérdida de la exoneración.

En nuestra posición, consideramos que por la forma en como está redacta la Ley, la primera posición es la correcta, por las siguientes razones:

1. Desde el ámbito tributario, consideramos que para encontrar el concepto del requisito destino de la renta, necesariamente debemos remitirnos a la Ley del Impuesto a la Renta donde encontramos la definición de "renta". De acuerdo al ámbito de aplicación del impuesto establecido en la Ley del Impuesto a la Renta, se consideran rentas, a las provenientes de la renta- producto, flujos de riqueza y consumo más incremento patrimonial. Ahora, si bien las entidades no lucrativas pueden obtener rentas provenientes de las tres teorías de renta, la Ley del Impuesto a la Renta no alcanza a gravar de per se el patrimonio (ejemplo los aportes de los asociados) de la entidad. Si bien las cuentas patrimoniales de la entidad podrían gravarse con el impuesto a la renta, esto solo podría efectuarse con la aplicación de las normas de presunción de rentas establecidas en la Ley.

2. Desde un aspecto económico, el aporte de capital no genera utilidades para la entidad. El aporte social es solo una herramienta de financiamiento, como son los préstamos bancarios, en el que, la operación de acuerdo a las normas contables no constituye ingresos que afecten a los resultados, sino solo la presencia de un activo contra una cuenta de pasivo (obligación). Esto significa que los aportes de los asociados no generan rentas para la entidad, por lo tanto, en la medida que la entidad demuestre que el monto de los activos dispuestos no excede el monto de los aportes, no se podría afirmar que se haya incumplido el requisito del destino de la renta, y por lo tanto se pretenda retirar la exoneración de la entidad. 


\subsubsection{El monto del destino}

Como hemos mencionado, el referido inciso b) del artículo $19^{\circ}$ de la Ley del Impuesto a la Renta, establece que, para gozar de la exoneración del impuesto, las rentas deben destinarse al fin, sin embargo, la Ley no ha establecido cuál es el monto de la renta que debe ser destinado. Una primera posición es, bajo la literalidad de la Ley, que no existe ninguna excepción, por lo tanto, toda la renta debe ser destinada al fin. Una segunda posición es, que la Ley al no haber precisado el monto del destino, bastaría se destine parte de la renta para que el requisito se entienda por cumplido.

Respecto a la primera posición, consideramos que cuando la Ley establece que las rentas se destinen al fin, efectivamente se está refiriendo a toda la renta, en tanto no considerar una parte de ella, se estaría arbitrariamente excluyendo parte de la renta. Mientras por la segunda posición, la cual refutamos, consideramos cuando la Ley se ha referido a destinar las rentas, no ha precisado ninguna exclusión de ellas, ni de monto ni procedencia, por lo que para que estas puedan quedar liberadas del pago del impuesto, necesariamente deben ser destinadas todas las rentas al fin social.

Respecto al monto del destino, es importante resaltar que el Estado con la actual legislación, no solo demanda que las entidades no lucrativas entreguen al fin una porción de sus rentas, si no condiciona que todas las rentas sean destinadas al fin, mientras que, para el caso de las sociedades lucrativas, la demanda solo abarca a una porción de la renta, que corresponde a la cuantía del impuesto. Esto quiere decir, que la injerencia del Estado en las entidades lucrativas es solo respecto a la porción del impuesto, dejando a plena libertad el remanente de la renta, mientras que, para las entidades no lucrativas, el control no se limita al monto del impuesto no recaudado, sino que supervisa toda la renta de la entidad. Sobre lo mismo, si el fisco hubiera gravado los ingresos de las entidades no lucrativas, solo hubiera recaudado de impuestos el $29.5 \%$ de la renta neta imponible, y toda la diferencia se hubiera dejado a libre disposición de los asociados, con lo cual el Estado hubiera dispuesto solo una parte de la renta para cumplir con su función estatal, como por ejemplo atender las necesidades sociales de las personas. Por lo tanto, el Estado, al no gravar las rentas de las entidades no lucrativas se podría estar beneficiando indirectamente con el total de la renta, debido a que la entidad deberá entregar la totalidad de sus rentas a los fines sociales que el Estado a su criterio ha elegido en el inciso b) del artículo $19^{\circ}$ de la Ley del Impuesto a la Renta, y que en esencia muchos de esos fines no serían de interés de toda entidad. 
Ahora bien, respeto al monto de la renta que debe ser destinada al fin, consideramos que la Ley bajo su potestad tributaria ha establecido que toda la renta debe necesariamente ser destinada al fin social, sin embargo, no se ha plasmado el momento de su destino, tema que abordamos a continuación.

\subsubsection{Respecto al momento del destino}

Luego de discernir sobre el monto de la renta que debe ser destinado al fin, queda por analizar la controversia más importante de este trabajo, la cual también está relacionada con el requisito del destino de la renta, pero ahora respecto al momento en que se debe efectuar el destino. La norma no ha estipulado el momento, ni los plazos para cumplir con el acto de destinar la renta, lo cual ha dado con controversias que hasta la fecha no se ha resuelto.

\section{- Controversias respecto al momento de cumplir con el destino}

La falta de una correcta definición del momento en que se debe de cumplir con el requisito del "destino de la renta" ha generado dos siguientes controversias:

1. Para que las rentas gocen de la exoneración previamente estas se deben haber destinado al fin, por lo que sin ello no se habría cumplido con los requisitos dispuestos en la Ley del Impuesto a la Renta.

2. La Ley no ha establecido ningún plazo para efectuar el destino, por lo que bien podría la renta mantenerse en el patrimonio de la entidad por un plazo indeterminado, sin el riesgo de infringir los requisitos de la Ley del Impuesto a la Renta.

Respecto a la primera posición, el sostener que las rentas previamente deben destinarse al fin, es impracticable, toda vez que según nuestra legislación, la renta neta imponible se determina una vez cerrado el ejercicio fiscal, para lo cual se cuenta con un plazo de acuerdo al cronograma de pagos establecidos por la SUNAT, el que vence el año siguiente al ejercicio que dio origen a la renta, por lo que en el mejor de los escenarios la exigencia de destinar la renta se podría cumplir hasta el vencimiento de la declaración anual, tiempo que sería muy reducido para ejecutar el destino de la renta anual. Por esta 
razón, a menos que la norma establezca una disposición de "destinos a cuenta" durante el ejercicio, no podría pretenderse exigir que para gozar de la exoneración la renta previamente sea destinada.

En tanto a la segunda posición, sostenemos que efectivamente la Ley del Impuesto a la Renta no ha establecido el momento en que la renta debe de ser destinada al fin, por lo tanto, mientras las rentas permanezcan en las arcas de la entidad no se incurriría en una causal de pérdida de la exoneración. Ahora bien, la forma de permanencia de las rentas en la entidad podría presentarse de diversas formas:

1. Las rentas podrían permanecer en la caja de la entidad.

2. Las rentas podrían re investirse en activos fijos destinado a los fines de la entidad.

3. Las rentas podrían re invertirse en activos fijos destinados a las actividades empresariales de la entidad.

4. Las rentas podrían re invertirse en la adquisición de valores emitidos por entidades lucrativas con la expectativa de obtener rentabilidad.

En nuestra posición, el acto de trasladar la renta a las actividades empresariales que ella realiza, no incumple con los requisitos del goce de la exoneración, en tanto todos estos activos permanecen bajo la propiedad (patrimonio) de la entidad, y su uso tiene como objetivo generar rentas empresariales que finalmente retornarán para el cumplimiento del fin social. Sin embargo, en este escenario, el riesgo es que con el paso del tiempo estas inversiones no retornen al fin social de la entidad.

\section{- El retorno de la renta}

De acuerdo a la Ley del Impuesto a la Renta, el requisito es que la renta se destine al fin, sin embargo, por lo expresado, las rentas invertidas en las actividades empresariales no vienen retornando al fin social. Por el contrario, las inversiones empresariales de las entidades no lucrativas vienen aportando al desarrollo de líneas de negocios empresariales, que finalmente consumen las rentas; manteniendo cargas laborales, gastos de asesorías, gastos por publicidad, entre otros, que al final la renta es consumida. Incluso, muchas entidades no lucrativas, con el pretexto de obtener rentas, invierten en valores negociables, los cuales 
muchos de ellos son para financiar a empresas donde a través de sus gastos consumen la utilidad, quienes al cierre del ejercicio obtienen pérdidas financieras, y finalmente la entidad no lucrativa no recupera su inversión.

Es por esta razón, que existe la necesidad que la Ley, introduzca un plazo máximo para que las entidades cumplan con efectuar la renta a los fines sociales, para lo cual sugerimos establecer un plazo máximo de 03 (tres) años para que la renta efectivamente se destine al fin. Consideramos este tiempo por dos razones:

1) Para que la entidad disponga de un tiempo razonable para efectuar el destino de la renta.

2) Para facilitar el proceso de fiscalización de la Administración Tributaria durante los periodos no prescritos.

Con la incorporación de esta disposición, las entidades dispondrían dentro de la Ley, una disposición clara del destino de la renta, que otorgue seguridad jurídica, asimismo, la Administración Tributaria podría fiscalizar correctamente el cumplimiento de los requisitos de la exoneración, y por último el fisco se aseguraría que las rentas exoneradas se destinen a los fines elegidos.

\subsection{Legislación Comparada}

\subsubsection{Tratamiento fiscal español de las entidades no lucrativas}

De acuerdo a la legislación española, Ley 27/2014 de 27 de noviembre, del Impuesto sobre Sociedades, en el desarrollo de la hipótesis de incidencia, deja establecido que las operaciones de las entidades sin fines de lucro pueden encontrase dentro del ámbito de aplicación del impuesto, y para esta Ley, por su constitución jurídicamente se encuentran contemplados como contribuyentes del impuesto. Por lo que, es necesario analizar qué tipo de exención del impuesto la legislación española ha otorgado a las entidades no lucrativas.

\section{- De las exenciones del impuesto}


La Ley española denominada Impuesto sobre Sociedades, en el artículo $9^{\circ}$, estable tres apartados que se refieren a la exención parcial del Impuesto:

Primero, se establece:

Estarán parcialmente exentas del Impuesto, en los términos previstos en el Título II de la Ley 49/2002, de 23 de diciembre, de régimen fiscal de las entidades sin fines lucrativos y de los incentivos fiscales al mecenazgo, las entidades e instituciones sin ánimo de lucro a las que sea de aplicación dicho título. (Ley N. ${ }^{\circ}$ 27/2014, 2014, art. 9)

Segundo, dispone:

Estarán parcialmente exentas del Impuesto en los términos previstos en el capítulo XIV de título VII de esta Ley:

a) Las entidades e instituciones sin ánimo de lucro no incluidas en el apartado anterior.

b) Las uniones, federaciones y confederaciones de cooperativas.

c) Los colegios profesionales, las asociaciones empresariales, las cámaras oficiales y los sindicatos de trabajadores.

d) Los fondos de promoción de empleo constituidos al amparo del artículo veintidós de la Ley 27/1984, de 26 de julio, sobre reconversión y reindustrialización. (Ley N. ${ }^{\circ}$ 27/2014, 2014, art. 29)

e) $\ldots$

Tercero, refiere:

"Estarán parcialmente exentos del Impuesto los partidos políticos, en los términos establecidos en la Ley Orgánica 8/2007, de 4 de julio, sobre financiación de los partidos políticos. (Ley N. ${ }^{\circ}$ 27/2014, 2014, art. 9)

De los tres apartados que la legislación española ha establecido, encontramos por los menos cuatro aspectos importantes que llaman la atención en comparación a la legislación peruana:

1) La Ley española no habla de exoneración, sino de exención.

2) La Ley española expresamente se refiere la exención parcial. 
3) La Ley española al otorgar la exención, además de las entidades tipificadas en la Ley general, adiciona a otro grupo de exentos a través de una ley especial, la Ley 49/2002, de 23 diciembre del Régimen Fiscal de las Entidades sin Fines Lucrativos y los Incentivos Fiscales al Mecenazgo.

4) La Ley española al otorgar la exención, además del listado de entidades exentas, remite a otro grupo de entidades referidas en un capítulo especial (Capítulo XIV de título VII) de la Ley.

\section{- Ley de entidades sin fines de lucro y de los incentivos fiscales al mecenazgo}

El Estado español a través de la Ley 49/2002 Entidades sin Fines de Lucro y de los Incentivos Fiscales al Mecenazgo, ha otorgado una regulación especial para las entidades sin fines lucrativos. En esta Ley encontramos disposiciones importantes que sirven como legislación comparada para nuestro trabajo de investigación.

\section{Entidades sin fines lucrativos}

El artículo $2^{\circ}$, cuando se refiere a las entidades sin fines lucrativos dentro del alcance de esta Ley, entre otras entidades, incluye a las federaciones y asociaciones sin fines lucrativos a que se refieren los párrafos anteriores.

\section{Requisitos de las entidades sin fines lucrativos}

En la ley sobre Régimen Fiscal de las Entidades sin Fines de Lucro y de los Incentivos Fiscales, cuando se refiere a los requisitos de las entidades sin fines lucrativos, establece:

Las entidades a que se refiere el artículo anterior, que cumplan los siguientes requisitos serán consideradas, a efectos de esta Ley, como entidades sin fines lucrativos:

1. ${ }^{\circ}$ Que persigan fines de interés general, como pueden ser, entre otros, los de defensa de los derechos humanos, de las víctimas del terrorismo y actos violentos, los de asistencia social e inclusión social, cívicos, educativos, culturales, científicos, deportivos, sanitarios, laborales, de fortalecimiento institucional, de cooperación para el desarrollo, de promoción del voluntariado, 
de promoción de la acción social, defensa del medio ambiente, de promoción y atención a las personas en riesgo de exclusión por razones físicas, económicas o culturales, de promoción de los valores constitucionales y defensa de los principios democráticos, de fomento de la tolerancia, de fomento de la economía social, de desarrollo de la sociedad de la información, de investigación científica, desarrollo o innovación tecnológica y de transferencia de la misma hacia el tejido productivo como elemento impulsor de la productividad y competitividad empresarial. (Ley 49/2002, 2002, art. 3)

Si bien el primer requisito descrito en el numeral $1 .^{\circ}$ del artículo 3, nos muestra grandes similitudes de los fines con respecto a la legislación peruana, es el numeral 2. ${ }^{\circ}$ quien nos entrega una interesante regulación de requisitos de las entidades no lucrativas que sirven como legislación comparada para nuestro trabajo de investigación, el cual establece:

2. ${ }^{\circ}$ Que destinen a la realización de dichos fines al menos el 70 por 100 de las siguientes rentas e ingresos:

a) Las rentas de las explotaciones económicas que desarrollen.

b) Las rentas derivadas de la transmisión de bienes o derechos de su titularidad. En el cálculo de estas rentas no se incluirán las obtenidas en la transmisión onerosa de bienes inmuebles en los que la entidad desarrolle la actividad propia de su objeto o finalidad específica, siempre que el importe de la citada transmisión se reinvierta en bienes y derechos en los que concurra dicha circunstancia.

c) Los ingresos que obtengan por cualquier otro concepto, deducidos los gastos realizados para la obtención de tales gastos. Los gastos realizados para la obtención de tales ingresos podrán estar integrados, en su caso, por la parte proporcional de los gastos por servicios exteriores, de los gastos de personal, de otros gastos de gestión, de los gastos financieros y de los tributos, en cuanto que contribuyan a la obtención de ingresos, excluyendo de este cálculo los gastos realizados para el cumplimiento de los fines estatutarios o del objeto de la entidad sin fines lucrativos. En el cálculo de los ingresos no se incluirán las aportaciones o donaciones recibidas en 
concepto de dotación patrimonial en el momento de su constitución o en un momento posterior.

Las entidades sin fines lucrativos deberán destinar el resto de las rentas e ingresos a incrementar la dotación patrimonial o las reservas.

El plazo para el cumplimiento de este requisito será el comprendido entre el inicio del ejercicio en que se haya obtenido las respectivas rentas e ingresos y los cuatro años siguientes al cierre de dicho ejercicio. (Ley 49/2002, 2002, art. 3)

Con el segundo requisito descrito en el numeral 2. ${ }^{\circ}$ la Ley especial española introduce un requisito que no encontramos en la legislación peruana, la cual demanda que las entidades no lucrativas destinen a sus fines un porcentaje mínimo de sus ingresos o rentas provenientes de sus actividades empresariales. En este caso, para que una entidad española sea reconocida como entidad sin fines lucrativos, necesariamente debe destinar a sus fines un porcentaje no menor al $70 \%$ de sus ingresos o rentas provenientes de sus actividades económicas (empresariales), y solo con el cumplimiento de este requisito podrían acogerse al pago del impuesto parcial, bajo las exenciones contempladas en la Ley 27/2014 Impuesto a las Sociedades.

Adicionalmente, la Ley española introduce un tercer requisito en el numeral $3 .^{\circ}$ del artículo $3^{\circ}$ de la Ley para que una entidad pueda ser considerada como entidad sin fines lucrativos, donde se dispone:

3. ${ }^{\circ}$ Que la actividad realizada no consista en el desarrollo de explotaciones económicas ajenas a su objeto o finalidad estatutaria. Se entenderá cumplido este requisito si el importe neto de la cifra de negocios del ejercicio correspondiente al conjunto de las explotaciones económicas no exentas ajenas a su objeto o finalidad estatutaria no excede del 40 por 100 de los ingresos totales de la entidad, siempre que el desarrollo de estas explotaciones económicas no exentas no vulnere las normas reguladoras de defensa de la competencia en relación con empresas que realicen la misma actividad. 
A efectos de esta Ley, se considera que las entidades sin fines lucrativos desarrollan una explotación económica cuando realicen la ordenación por cuenta propia de medios de producción y de recursos humanos, o de uno de los ambos, con la finalidad de intervenir en la producción o distribución de bienes o servicios. El arrendamiento del patrimonio inmobiliario de la entidad no constituye, a estos efectos, explotación económica. (Ley 49/2002, 2002, art. 3)

En el referido numeral $3 .^{\circ}$ encontramos un requisito adicional que tampoco se encuentra en la legislación peruana, donde se reconoce a una entidad sin fines lucrativos, siempre y cuando el monto de sus actividades o explotaciones económicas gravadas con el impuesto, no supere el $40 \%$ de los ingresos totales de la entidad. Asimismo, la norma otorga un tratamiento diferenciado para los ingresos provenientes de los arrendamientos de los activos de la entidad, disponiendo que estos ingresos aun cuando son actividades económicas, no sean considerados para el cálculo del límite establecido.

\section{Rentas exentas}

La Ley 49/2002 en el Capítulo II establece el Impuesto sobre las Sociedades, donde en sus artículos en resumen dispone lo siguiente:

En el artículo $6^{\circ}$ se aborda sobre las rentas exentas, además, se otorga una relación de ingresos de las entidades sin fines lucrativos considerados como rentas exentas del impuesto, como son: 1) Las donaciones obtenidas, las cuotas de los asociados, y las subvenciones, 2) Los procedentes del patrimonio mobiliario en inmobiliario de la entidad, como son los dividendos obtenidos de sociedades, los intereses, cánones y alquileres, y 3) Los obtenidos por disolución y liquidación de la entidad.

\section{Explotaciones económicas exentas}

En el artículo $7^{\circ}$ se plasman las explotaciones exentas, en él se establece que están exentas del impuesto las rentas las explotaciones económicas, siempre y cuando sean desarrolladas en el cumplimiento de su objeto o finalidad específica, entre las que destacan las explotaciones económicas: 1) 
Desarrolladas en la asistencia social e inclusión social, 2) Que presten servicios de hospitalización o asistencia sanitaria, 3) De investigación científica y desarrollo tecnológico, etc.

Lo que resalta del artículo $7^{\circ}$ de esta Ley, es el numeral $11^{\circ}$ donde se incluye como renta exenta a las rentas de explotación económica que tengan un carácter meramente auxiliar o complementario de las explotaciones económicas exentas o de las actividades encaminadas a cumplir el fin estatutario, pero no serán consideradas como explotaciones económicas de carácter meramente auxiliar o complementario cuando el importe neto de la cifra de negocios del ejercicio correspondiente al conjunto de ellas exceda de 20 por ciento de los ingresos totales de la entidad. Y, por último, de acuerdo al párrafo 14 de este artículo, menciona, que las explotaciones económicas de escasa relevancia, serán consideradas como tales, cuando su importe neto de la cifra de negocios del ejercicio no supere en conjunto 20,000 euros.

\section{Respecto de la determinación de la base imponible}

En el artículo $8^{\circ}$ la Ley 49/2002 (2002) dispone reglas para determinar la base imponible:

En la base imponible del Impuesto sobre Sociedades de las entidades sin fines lucrativos sólo se incluirán las rentas derivadas de las explotaciones económicas no exentas.

No tendrán la consideración de gastos deducibles, además de los establecidos por la norma general del Impuesto a las Sociedades, los siguientes:

a) Los gastos imputables exclusivamente a las rentas exentas.

Los gastos parcialmente imputables a las rentas no exentas serán deducibles en el porcentaje que representen los ingresos obtenidos en el ejercicio de explotaciones económicas no exentas respecto de los ingresos totales de la entidad.

b) Las cantidades destinadas a la amortización de elementos patrimoniales no afectos a las explotaciones económicas sometidas a gravamen.

En el caso de elementos patrimoniales afectos parcialmente a la realización de actividades exentas, no resultarán deducibles las cantidades destinadas 
a la amortización en el porcentaje en que el elemento patrimonial se encuentre afecto a la realización de dicha actividad.

c) Las cantidades que constituyan aplicación de resultados y, en particular, de los excedentes de explotaciones económicas no exentas.

Con el referido artículo $8^{\circ}$ la Ley otorga un tratamiento especial para determinar la base imponible del impuesto, donde resalta la deducción de los gastos bajo el sistema de prorrateo de los gastos relacionad os a las rentas gravadas y las rentas exentas.

\section{Respecto al tipo de gravamen}

Así también, la Ley 49/2002 (2002) establece el tipo de gravamen para las rentas de las entidades sin fines lucrativos:

"La base imponible positiva que corresponda a las rentas derivadas de explotaciones económicas no exentas será gravada al tipo del 10 por 100”. (art. 10)

Un aspecto por resaltar es que, a diferencia de la legislación peruana, en la legislación española, una norma especial determina el porcentaje de la tasa de gravamen del impuesto, que, si bien la legislación general del Impuesto a las Sociedades también establece la misma tasa, no sucede lo mismo en el Perú, donde la cuantía del impuesto solo es establecida en la norma general dada por Ley del Impuesto a la Renta.

\section{Respecto de las obligaciones contables}

Por último, en la Ley 49/2002 (2002) se dispone:

Las entidades sin fines lucrativos que obtengan rentas de explotaciones económicas no exentas del Impuesto sobre Sociedades tendrán las obligaciones contables previstas en las normas reguladoras de dicho impuesto. La contabilidad de estas entidades se llevará de tal forma que permita identificar los ingresos y gastos correspondientes a las de explotaciones económicas no exentas. (art. 11)

Con este artículo el físco español, a diferencia del peruano, si cuenta con una disposición expresa respecto a la contabilidad de las entidades no lucrativas, en la que 
solicita el llevado de la contabilidad por líneas de negocios, controlando los ingresos y gastos de las explotaciones económicas gravadas y las exentas, todo con la finalidad de poder fiscalizar la base imponible del impuesto.

\section{- Tipo de gravamen dentro de la Ley de Impuesto sobre Sociedades}

La legislación española establece tasas diferenciadas para el pago del impuesto, determinando para entidades la siguiente cuantía:

Tributarán al 10 por ciento las entidades a las que sea de aplicación el régimen fiscal establecido en la Ley 49/2002, de 23 de diciembre, de régimen fiscal de las entidades sin fines lucrativos y de los incentivos fiscales al mecenazgo. (Ley N. ${ }^{\circ}$ 27/2014, 2014, art. 29)

\subsubsection{Tratamiento fiscal mexicano de las entidades no lucrativas}

\section{- Del ámbito de la ley del impuesto a la renta en México}

De acuerdo a la legislación mexicana, con la Ley del Impuesto sobre la Renta bajo la última reforma publicada DOF 30-11-2016, en el Título I de las Disposiciones Generales, deja establecido que las operaciones de las entidades sin fines de lucro pueden calificarse como rentas dentro del ámbito de aplicación del impuesto, y son consideradas como contribuyentes del impuesto en calidad de personas morales. Por lo que, es necesario analizar qué tipo de exención ha otorgado la legislación mexicana para las entidades no lucrativas.

\section{- De las exenciones del impuesto}

La legislación tributaria mexicana, con Ley del Impuesto sobre la Renta, artículo $79^{\circ}$ del Título III del Régimen de las Personas Morales con Fines no Lucrativos, presenta un listado voluminoso de XXVI formas de entidades calificadas como no lucrativas, cada una con su propia definición y la mayoría de ellas con su propio listado de actividades autorizadas para desarrollar, lo cual guarda mucha diferencia con la escueta legislación tributaria peruana. 
La ley tributaria mexicana, a diferencia de la legislación peruana, en la Ley del Impuesto Sobre la Renta, plasma una regulación respecto a las actividades empresariales, estableciendo:

En el caso de que las personas morales a que se refiere este Título enajenen bienes distintos de su activo fijo o presten servicios a personas distintas de sus miembros o socios, deberán determinar el impuesto que corresponda a la utilidad por los ingresos derivados de las actividades mencionadas, en los términos del Título II de esta Ley, a la tasa prevista en el artículo 9 de la misma, siempre que dichos ingresos excedan del $5 \%$ de los ingresos totales de la persona moral en el ejercicio de que se trate. (Ley del Impuesto Sobre la Renta. DOF 30-11-2016, 2016, art. $80)$.

La norma mexicana a diferencia de la peruana, otorga una disposición que activa el hecho imponible del impuesto, cuando las entidades morales no lucrativas enajenen bienes distintos a su activo fijo, y/o preste servicios a personas distintas de sus miembros o socios. Esto quiere decir, que la norma mexicana no otorga la exención a todas las rentas obtenidas por las entidades morales no lucrativas, sino más bien demanda gravar a las actividades empresariales como la compra y venta de mercancías o la prestación de servicios realizadas por las entidades no lucrativas.

Asimismo, siguiendo el mismo criterio, de acuerdo al artículo $81^{\circ}$ de la Ley mexicana, a diferencia de la peruana, se establece que las personas morales no lucrativas, salvo algunas excepciones, serán contribuyentes del impuesto sobre la renta cuando perciban ingresos por enajenación de bienes, intereses y premios.

Por otra parte, se establece que se deberá cumplir con estrictas disposiciones para alcanzar la condición de instituciones autorizadas para recibir donativos deducibles, dentro de los cuales destaca la fracción IV, donde a la letra dice:

IV. Que destinen sus activos exclusivamente a los fines propios de su objeto social, no pudiendo otorgar beneficios sobre el remanente distribuible a persona física alguna o a sus integrantes personas físicas o morales, salvo que se trate, en éste último caso, de alguna de las personas morales o fideicomisos autorizados para recibir donativos deducibles de impuestos o se trate de la remuneración de 
servicios efectivamente recibidos. (Ley del Impuesto sobre la Renta. DOF 30-112016, 2016, art. 82)

Sobre la mencionada fracción IV, en el Reglamento de la Ley del Impuesto sobre la Renta, se dispone:

Para efectos del artículo $82^{\circ}$, fracción IV de la Ley, se estará a lo siguiente:

Los donativos y sus rendimientos deberán destinarse únicamente y exclusivamente a los fines propios del objeto social autorizado de las donatarias. En ningún caso podrán dichas donatarias destinar más del 5\% de los donativos y, en su caso, de los rendimientos que perciban para cubrir sus gastos de administración.

Para efectos del párrafo anterior, se consideran gastos de administración entre otros, los relacionados con las remuneraciones al personal, arrendamiento de bienes muebles e inmuebles, teléfono, electricidad, papelería, mantenimiento y conservación, los impuestos y derechos federales o locales, así como las demás contribuciones y aportaciones que en términos de las disposiciones legales respectivas deba cubrir la donataria siempre que se efectúen en relación directa con las oficinas o actividades administrativas. No quedan comprendidos en los gastos de administración, aquellos que la donataria deba destinar directamente para cumplir con los fines propios de su objeto social. (Reglamento de la Ley del Impuesto Sobre la Renta. DOF 06-05-2016, 2016, art. 138)

Lo dispuesto por el Reglamento mexicano, nos otorga una idea interesante como legislación comparada, debido que, a diferencia de la legislación peruana, se introduce una disposición que limita la disposición de las rentas para fines diferentes de la entidad, incluso si la disposición estuviera destinada para cubrir los gastos administrativos de la entidad.

\subsection{Propuesta legislativa}

\subsubsection{Modificación de la Ley del Impuesto a la Renta}

\section{- Fundamentos}

\section{Situación actual}


Conforme a lo dispuesto en el inciso b) del artículo $19^{\circ}$ de la Ley del Impuesto a la Renta, están exoneradas del Impuesto hasta el 31 de diciembre del 2020, excepto el inciso b) que está exonerado hasta el 31 de diciembre de 2019, las rentas de fundaciones afectas y de asociaciones sin fines de lucro cuyo instrumento de constitución comprenda exclusivamente, alguno o varios de los siguientes fines: beneficencia, asistencia social, educación, cultura, científica, artística, literaria, deportiva, política, gremiales, y/o de vivienda; siempre que destinen sus rentas a sus fines específicos en el país; no las distribuyan, directa o indirectamente, entre los asociados o partes vinculadas a estos o a aquellas, y que en sus estatutos esté previsto que su patrimonio se destinará, en caso de disolución, a cualquiera de los fines contemplados en este inciso.

Respecto del requisito del destino de la renta a los fines específicos en el país, la norma no hace ninguna precisión adicional.

\section{Problemática}

Como se aprecia en el inciso b) del artículo $19^{\circ}$ de la Ley se exonera del Impuesto a las rentas a las entidades que cumplan de manera conjunta los siguientes requisitos:

(i) Su instrumento de constitución comprenda exclusivamente, alguno o varios de los fines que la Ley establece.

(ii) Que las rentas se destinen a los fines específicos en el país.

(iii) Que las rentas no se distribuyan, directa ni indirectamente, entre sus asociados o partes vinculadas a estos o a aquellas.

(iv) Que en su estatuto esté previsto que su patrimonio se destinará, en caso de disolución, a cualquiera de los fines contemplados en este inciso.

Si bien la Ley ha tratado de incluir requisitos que buscan evitar la evasión tributaria de las entidades sin fines de lucro, nuestro trabajo de investigación ha detectado una debilidad en la actual legislación tributaria, debido que no dispone de una correcta definición del requisito denominado destino de la renta.

Haciendo una recopilación del problema planteado en este trabajo de investigación, encontramos que las entidades sin fines de lucro:

$1^{\mathrm{o}}$ Tienen la permisividad de realizar actividades empresariales sin incurrir en causal de pérdida de la exoneración. 
$2^{\circ}$ Vienen derivando sus rentas a actividades empresariales sin causal de pérdida de la exoneración.

$3^{\circ}$ No disponen de un plazo establecido en la Ley del Impuesto a la Renta para que sus rentas sean destinadas efectivamente a sus fines sociales.

$4^{\circ}$ Por la ausencia de un plazo establecido en la Ley del Impuesto a la Renta no vienen cumpliendo con destinar la renta a los fines sociales.

Las razones expresadas, nos conllevan a plantear una propuesta legislativa que corrija el problema, para lograr el verdadero propósito que el Estado consideró al establecer la exoneración del impuesto a la renta para las entidades sin fines de lucro, que en esencia debe buscar que todos los beneficios obtenidos por las entidades no lucrativas beneficien directamente al sector que por política fiscal el Estado ha deseado.

\section{Propuesta:}

Consideramos que, para evitar que las entidades sin fines de lucro deriven las rentas a actividades empresariales, y que dichos fondos permanezcan por tiempo indeterminado en ellas, sin retornar al fin social, es necesario modificar el primer párrafo del inciso b) del artículo $19^{\circ}$ de la ley del Impuesto a la Renta.

\section{Texto actual:}

"Están exoneradas del Impuesto hasta el 31 de diciembre del 2020, excepto el inciso b), que está exonerado hasta el 31 de diciembre de 2019.

\section{$(\ldots)$}

b) Las rentas de fundaciones afectas y de asociaciones sin fines de lucro cuyo instrumento de constitución comprenda exclusivamente, alguno o varios de los siguientes fines: Beneficencia, asistencia social, educación, cultura, científica, artística, literaria, deportiva, política, gremiales, y/o de vivienda; siempre que destinen sus rentas a sus fines específicos en el país; no las distribuyan, directa o indirectamente, entre los asociados o partes vinculadas a estos o a aquellas, y que en sus estatutos esté previsto que su patrimonio se destinará, en caso de disolución, a cualquiera de los fines contemplados en este inciso". 
$(\ldots)$

\section{Texto sugerido:}

"Están exoneradas del Impuesto hasta el 31 de diciembre del 2020, excepto el inciso b), que está exonerado hasta el 31 de diciembre de 2019.

\section{$(\ldots)$}

b) Las rentas de fundaciones afectas y de asociaciones sin fines de lucro cuyo instrumento de constitución comprenda exclusivamente, alguno o varios de los siguientes fines: Beneficencia, asistencia social, educación, cultura, científica, artística, literaria, deportiva, política, gremiales, y/o de vivienda; siempre que destinen sus rentas a sus fines específicos en el país en el plazo no mayor a 3 años posteriores al ejercicio de su determinación; no las distribuyan, directa o indirectamente, entre los asociados o partes vinculadas a estos o a aquellas, y que en sus estatutos esté previsto que su patrimonio se destinará, en caso de disolución, a cualquiera de los fines contemplados en este inciso".

\section{$(\ldots)$}

\section{Efecto sobre la legislación nacional}

La propuesta implica modificar el primer párrafo del inciso b) del artículo $19^{\circ} \mathrm{de}$ la Ley del Impuesto a la Renta.

\section{- Análisis costo - beneficio}

La norma que se propone tiene por objeto:

1. Otorgar mayor seguridad jurídica en la aplicación de los requisitos para la exoneración.

2. Dotar de parámetros para evaluar el cumplimiento del requisito.

3. Permitir el mejor control de la elusión tributaria.

En tal sentido, resulta beneficioso para los contribuyentes que las normas otorguen seguridad jurídica, así les permite cumplir los requisitos de la exoneración sin inconsistencias.

De otro lado, resulta beneficioso al fisco en la medida que la norma evita que los contribuyentes desarrollen planeamientos tributarios elusivos con la finalidad de obtener una ventaja fiscal de forma indebida. 


\subsubsection{Inclusión en el Reglamento del Impuesto a la Renta}

\section{- Fundamentos}

\section{Situación actual}

De acuerdo al actual Reglamento del Impuesto a la Renta otorgado por el Decreto Supremo $N^{\circ}$ 122-94-EF no se ha fijado ninguna reglamentación respecto del requisito del destino de la renta a los fines específicos.

\section{Problemática}

\section{Propuesta}

Consideramos incorporar en el Reglamento del Impuesto a la Renta el siguiente artículo:

Artículo $8^{\circ}$-G.- Destino de la renta a sus fines específicos

Para efectos de lo dispuesto en el primer párrafo del inciso b) del artículo $19^{\circ} \mathrm{de}$ la Ley, se dará por cumplido el destino de la renta a sus fines específicos, cuando en el plazo establecido por la Ley:

a) La entidad invierta en activos fijos destinados íntegramente a los fines sociales, y/o,

b) La entidad incurra en costos o gastos directamente relacionados a los fines sociales.

Los desembolsos realizados en los incisos a) y b) en ningún caso pueden ser destinados a actividades empresariales. Asimismo, para el inciso b), como mínimo el $70 \%$ de los referidos desembolsos deberán ser incurridos en las áreas operativas de los fines sociales, y solo el saldo podrá destinarse a los gastos administrativos de la entidad que sirven de apoyo al cumplimiento del fin social.

\section{Efecto sobre la legislación nacional}

La incorporación de este artículo demanda la modificación del Reglamento de la Ley del Impuesto a la Renta. 
- Análisis costo - beneficio

La reglamentación que se propone tiene por objeto:

1. Otorgar una mayor precisión para el cumplimiento del requisito propuesto en la Ley del Impuesto a la Renta, respecto a la exigencia del destino de la renta con plazos establecidos.

2. Dotar de mayor precisión para medir la forma del destino de la renta a los fines establecidos y evitar que todas las rentas se deriven a gastos administrativos.

3. Permitir el mejor control de parte de la Administración Tributaria para medir los casos donde se configuren planeamientos tributarios diseñados para evadir o eludir los impuestos. 


\section{CONCLUSIONES}

A continuación, se detallan las siguientes conclusiones:

- En el marco del inciso b) del artículo $19^{\circ}$ de la Ley del Impuesto a la Renta, las entidades sin fines de lucro que desarrollan actividades empresariales, en tanto destinen sus rentas a los fines establecidos en la norma, no pierden el beneficio de la exoneración tributaria del impuesto a la renta.

- En aplicación del inciso b) del artículo $19^{\circ}$ de la Ley del Impuesto a la Renta, las entidades sin fines de lucro que destinen sus rentas a actividades empresariales, en tanto que estas generen beneficios para la entidad; no califican como causal de pérdida de la exoneración.

- El inciso b) del artículo $19^{\circ}$ de La Ley del Impuesto a la Renta no otorga una definición apropiada que permita verificar el cumplimiento del requisito denominado "destino de la renta para los fines específicos en el país" para el goce de la exoneración de las rentas de las entidades sin fines de lucro.

- Las entidades sin fines de lucro, por la ausencia de una correcta definición del "destino de la renta a los fines específicos", vienen derivando recursos de la entidad a las actividades empresariales, interrumpiendo el verdadero objetivo del Estado al otorgar la exoneración del impuesto a las rentas. 


\section{RECOMENDACIONES}

A continuación, debido a las conclusiones mencionadas, con la finalidad de corregir el problema, recomendamos:

- Modificar la Ley del Impuesto a la Renta con la finalidad de incluir parámetros de medición respecto a montos y plazos para poder evaluar el cumplimiento del requisito del destino de la renta a los fines específicos de las entidades sin fines de lucro.

- Incorporar en el Reglamento de la Ley del Impuesto a la Renta un artículo que describa la forma de hacer efectivo los montos y el cumplimiento de los plazos, para el cumplimiento del requisito del destino de la renta a los fines específicos de las entidades sin fines de lucro. 


\section{REFERENCIAS}

Real Academia Española (2018). Diccionario de la lengua española. Recuperado de http://www.rae.es/

Socías Salvá, A. y Herranz Bascones, R. (2013). Contabilidad de entidades sin fines lucrativos. Madrid: Pirámide.

Arevalo Mogollón, J. y Hirache Flores, L. (2010). Tratamiento Tributario de las Instituciones sin Fines de Lucro, Editores Pacífico. Lima: Instituto Pacífico SAC,

Constitución Política del Perú. (1993). Recuperado del sitio de internet del Congreso de la República del Perú: http://www4.congreso.gob.pe/ntley/Imagenes/Constitu/Cons1993.pdf

Ministerio de Justicia y Derechos Humanos. (2015). Código Civil (10. ${ }^{\mathrm{a}}$ ed.). Recuperado del sitio de internet del Sistema Peruano de Información Jurídica: http://spij.minjus.gob.pe/notificacion/guias/CODIGO-CIVIL.pdf

Fernández Ruiz, J. (2011). Derecho administrativo y administración Pública (4. ${ }^{a}$ ed.). Recuperado de http://www.diccionariojuridico.mx/definicion/personas-juridicasque-carecen-de-proposito-de-lucro/

García Mullin, R. (1980). Impuesto Sobre la Renta. Santo Domingo, República Dominicana.

Talledo Mazú, C. (2008). La Distribución de Utilidades en la Ley General de Sociedades. Recuperado de http://www.ipdt.org/uploads/docs/04_Rev13_CTM.pdf

Villegas, H. B. (2001). Curso de Finanzas, Derechos Financiero y Tributario (7.. ed.). [versión PDF]. Recuperado de http://www.ejuridicosalta.com.ar/files/libro9.pdf

Expediente N. ${ }^{\circ}$ 06403-2006-PA/TC. Sentencia del Tribunal Constitucional. Recuperado del sitio de internet del Tribunal Constitucional http://tc.gob.pe/jurisprudencia/2008/06403-2006-AA.pdf

Texto Único Ordenado de la Ley del Impuesto a la Renta. (08 de diciembre del 2004). Decreto Supremo N. ${ }^{\circ}$ 179-2004-EF. Recuperado del sitio de internet de la Superintendencia Nacional de Aduanas y de Administración Tributaria: http://www.sunat.gob.pe/legislacion/renta/ley/fdetalle.htm

Belaunde L de R. J. y Parodi Luna B. (1998). Marco Legal del Sector Privado sin Fines de Lucro en Perú. Apuntes, 43, 19-44. Recuperado de http://revistas.up.edu.pe/index.php/apuntes/article/view/476/478

Vega Mere, Y. (2013). La Constitución comentada (tomo 1, 2. ${ }^{\mathrm{a}}$ ed.). Lima: Gaceta Jurídica. 
Flores Gallegos, J. (2016). Tratamiento Tributario de las Entidades sin Fines de Lucro. Lima: Editorial Instituto Pacífico.

Expediente N. ${ }^{\circ}$ 246-95. (1997). Registro de Entidades Exoneradas del Impuesto a la Renta. Recuperado del sitio de internet del Tribunal Fiscal:

http://www.mef.gob.pe/contenidos/tribu_fisc/Tribunal_Fiscal/PDFS/1997/3/199 7_3_0891.pdf

Expediente N. ${ }^{\circ}$ 10904-94. (1998) Impuesto a la Renta. Recuperado del sitio de internet del Tribunal Fiscal:

http://www.mef.gob.pe/contenidos/tribu_fisc/Tribunal_Fiscal/PDFS/1998/1/199 8_1_0124.pdf

Superintendencia Nacional de Aduanas y de Administración Tributaria. (2018) Ingreso Anual recaudados. Tributos Internos por actividad económica y tributo. Recuperado de http://www.sunat.gob.pe/estadisticasestudios/ingresosrecaudados.html

Expediente N. ${ }^{\circ}$ 06188-4-2014. (2014) Impuesto a la Renta y Multa. Recuperado del sitio de internet del Tribunal Fiscal:

http://www.mef.gob.pe/contenidos/tribu_fisc/Tribunal_Fiscal/PDFS/2014/4/201 4_4_06188.pdf

Ley N. ${ }^{\circ}$ 27/2014, Modificaciones de la Ley del Impuesto sobre Sociedades. (27 de noviembre del 2014). Recuperado de: https://www.agenciatributaria.es/static_files/AEAT/Contenidos_Comunes/La_A gencia_Tributaria/Segmentos_Usuarios/Empresas_y_profesionales/Impuesto_so ciedades/Novedades_Impuesto_Sociedades_publicadas_2014/Comparativa_Soci edades_dic.pdf

Ley 49/2002, Régimen Fiscal de las Entidades sin Fines de Lucro y de los Incentivos Fiscales. (24 de diciembre del 2002). Recuperado del sitio de internet del Ministerio de la Presidencia, relaciones con las cortes e igualdad: https://www.boe.es/buscar/act.php?id=BOE-A-2002-25039

Ley del Impuesto Sobre la Renta. DOF 30-11-2016. (30 de noviembre del 2016). Recuperado del sitio de internet de la Cámara de Diputados: http://www.diputados.gob.mx/LeyesBiblio/pdf/LISR_301116.pdf

Reglamento de la Ley del Impuesto Sobre la Renta. DOF 06-05-2016. (06 de mayo del 2016). Recuperado del sitio de internet de la Cámara de Diputados: http://www.diputados.gob.mx/LeyesBiblio/regley/Reg_LISR_060516.pdf 